\title{
STATUS OF SOLAR SAIL TECHNOLOGY WITHIN NASA
}

\author{
Les Johnson, Roy Young, Edward Montgomery, and Dean Alhorn \\ NASA George C. Marshall Space Flight Center, Huntsville, Alabama, USA \\ Corresponding Author: Les Johnson (c.les.johnson@nasa.gov)
}

\begin{abstract}
In the early 2000s, NASA made substantial progress in the development of solar sail propulsion systems for use in robotic science and exploration of the solar system. Two different 20-m solar sail systems were produced and they successfully completed functional vacuum testing in NASA Glenn Research Center's (GRC's) Space Power Facility at Plum Brook Station, Ohio. The sails were designed and developed by ATK Space Systems and L'Garde, respectively. The sail systems consist of a central structure with four deployable booms that support the sails. These sail designs are robust enough for deployment in a one-atmosphere, one-gravity environment and were scalable to much larger solar sails_-perhaps as large as $150 \mathrm{~m}$ on a side. Computation modeling and analytical simulations were also performed to assess the scalability of the technology to the large sizes required to implement the first generation of missions using solar sails. Life and space environmental effects testing of sail and component materials were also conducted.
\end{abstract}

NASA terminated funding for solar sails and other advanced space propulsion technologies shortly after these ground demonstrations were completed. In order to capitalize on the $\$ 30 \mathrm{M}$ investment made in solar sail technology to that point, NASA Marshall Space Flight Center (MSFC) funded the NanoSail-D, a subscale solar sail system designed for possible small spacecraft applications. The NanoSail-D mission flew on board the illfated Falcon-1 Rocket launched August 2, 2008, and due to the failure of that rocket, never achieved orbit. The NanoSail-D flight spare will be flown in the Fall of 2010. This paper will summarize NASA's investment in solar sail technology to-date and discuss future opprortunities.

\section{INTRODUCTION}

Solar sail propulsion uses sunlight to propel vehicles through space by reflecting solar photons from a large, mirror-like sail made of a lightweight, reflective material. The continuous photonic pressure provides propellantless thrust to hover indefinitely at points in-space or conduct orbital maneuver plane changes more efficiently than conventional chemical propulsion. Eventually, it might propel a space vehicle to tremendous speeds - theoretically much faster than any present-day propulsion system. Because the Sun supplies the necessary propulsive energy, solar sails also require no onboard propellant, thus reducing payload mass.

First generation sails will vary in size from 100-200 m, depending on mission destination, and will typically be 3-axis stabilized. They will be compacted and stowed for launch. Once deployed, ultra-lightweight trusses will support the sails. Solar sails are composed of flat, smooth material covered with a reflective coating and supported by lightweight structures attached to a central hub. Near-term sails will likely use aluminized Mylar or CP1 ${ }^{\mathrm{TM}}$. Both are proven materials previously flown in space. More robust sails might use a meshwork of interlocking carbon fibers. 


\section{LARGE SOLAR SAIL SYSTEM LEVEL DEVELOPMENT}

\subsection{0-m Ground Demonstration Project}

NASA's In-Space Propulsion Technology Project funded the development of two prototype solar sail systems for ground testing to validate design concepts for sail manufacturing, packaging, and launch to space and deployment; attitude control subsystem function; and to characterize the structural mechanics and dynamics of the deployed sail in a simulated space environment. A square sail configuration consisting of a reflective sail membrane, a deployable sail support structure, an attitude control subsystem, and all hardware needed to stow the sail for launch were developed. In addition, these systems were required to meet the characteristics given in Table 1. A sub-L1 solar monitoring mission concept was also provided as a reference mission for guidance in design and scalability issues.

NASA awarded two ground demonstration contracts. ATK Space Systems' approach incorporated their rigid coilable boom, an articulating boom attitude control system (ACS) subsystem (modified to be a sliding mass), and partner SRS' CP1 $1^{\mathrm{TM}}$ sail membrane.$^{[1]} \mathrm{L}$ 'Garde Inc. used their inflatable and cold-temperature rigidizable boom, a control vane based ACS and Mylar ( for the sail membrane. ${ }^{[2]}$ The parallel testing and development of these two system-level demonstrations that have varied technologies in the three major components removed the risk to this technology development if one provider encountered an unrecoverable failure. The system-level ground demonstration work was divided into three phases. A 6-month concept refinement phase was completed in May 2003. During this phase, the two teams provided analysis of their system's performance when scaled to the Design Reference Mission and a preliminary test plan for the following two 12-month phases. The 12-month hardware development phase began in June 2003. In this phase both teams built and tested components and subsystems, with ATK concentrating on a single 10-m quadrant and L'Garde developing a 10-m square sail. The most comprehensive of these tests occurred in mid-2004 when the respective teams deployed their integrated subsystem in the NASA Langley Research Center (LaRC) 14-m vacuum facility (ATK) and the 30-m vacuum chamber at GRC's Plum Brook Space Power Facility (L'Garde). Following a successful second phase, the teams culminated their work in a 12-month system verification phase. In this phase both teams built and tested fully integrated $20-\mathrm{m}$ sail systems that included a launch packaging container and operational ACS subsystems. In mid2005, the respective teams tested their system in the Plum Brook Facility under a high vacuum and appropriate thermal environment, as well as subjecting their systems to launch vibration and ascent vent tests. Figure 1 shows the 20-m deployed systems at the Plum Brook Facility. Table 1 also summarizes the final performance metrics achieved by ATK and L'Garde with their 20 -m systems. Since these sails represent the largest systems that will be tested in a vacuum chamber on the ground, a significant effort was made to collect static and dynamic data on the sails and booms with $\sim 400 \mathrm{~Gb}$ of data collected, primarily raw photogrammetry data.
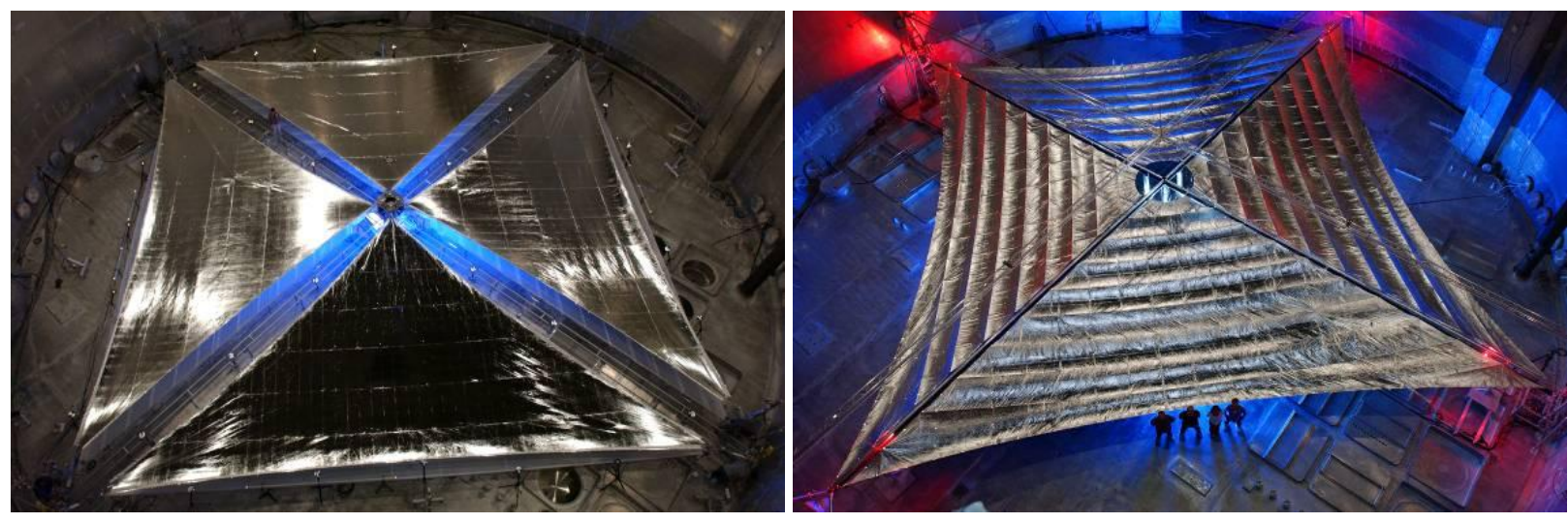

Fig. 1. Two 20-m solar sail prototypes are shown - ATK (left) and L'Garde (right). 
Table 1. System-level solar sail ground demonstration reporting metrics.

\begin{tabular}{|c|c|c|c|}
\hline Metric & RFP & ATK & L'Garde \\
\hline Dimensions & $\begin{array}{l}20 \text { meters } \times 20 \mathrm{~m} \text { or } \\
\text { greater }\end{array}$ & $\begin{array}{l}\text { - 20-m system with flightlike central } \\
\text { structure } \\
\text { - } 4 \text { sails scaled from } 80 \mathrm{~m} \\
\text { - Truncated } 80 \text {-m masts } \\
\text { - Central structure scaled from } 40 \mathrm{~m}\end{array}$ & $\begin{array}{l}\text { - } 19.5 \mathrm{~m} \text { due to Plumbrook } \\
\text { - } 1 \text { subscale TVCAD vane } \\
\text { - Nonflight central structure scaled } \\
\text { for } 100-\mathrm{m} \text { system } \\
\text { - Sails and mast truncated } 100-\mathrm{m} \\
\text { system }\end{array}$ \\
\hline $\begin{array}{l}\text { Sail Subsystem } \\
\text { Areal Density }\end{array}$ & $\begin{array}{l}<20 \mathrm{~g} / \mathrm{m}^{2} \\
(\mathrm{scalability} \text { to } \\
\left.12 \mathrm{~g} / \mathrm{m}^{2} \text { for } 104 \mathrm{~m}^{2}\right)\end{array}$ & $\begin{array}{l}\text { - } 112 \mathrm{~g} / \mathrm{m}^{2} \text { - includes spacecraft } \\
\text { bus structure, ACS, power, } \\
\text { instrument boom } \\
\text { - Scaled to } 11.3 \mathrm{~g} / \mathrm{m}^{2} \text { for } 100-\mathrm{m} \\
\text { design and no payload }\end{array}$ & $\begin{array}{l}\text { - } 30 \mathrm{~g} / \mathrm{m}^{2}-\text { includes ACS (4 vanes } \\
\text { calculated), central structure } \\
\text { dropped } \\
\text { - Scaled to } 14.1 \mathrm{~g} / \mathrm{m}^{2} \text { with } 50-\mathrm{kg} \\
\text { payload and } 41.4-\mathrm{kg} \text { bus }\end{array}$ \\
\hline Stowed Volume & $\begin{array}{l}<0.5 \mathrm{~m}^{3} \text { (scalability } \\
\text { to } 1.5 \mathrm{~m}^{3} \text { for } \\
104 \mathrm{~m}^{2} \text { ) }\end{array}$ & $\begin{array}{l}-0.9 \mathrm{~m}^{3} \text { scaled to } 1.5 \mathrm{~m}^{3} \text { for } 100-\mathrm{m} \\
\text { design }\end{array}$ & $\begin{array}{l}\text { - } 2.14 \mathrm{~m}^{3} \text { scaled to } 1.04 \mathrm{~m}^{3} \text { for } \\
100-\mathrm{m} \text { design }\end{array}$ \\
\hline $\begin{array}{l}\text { Thrust Vector } \\
\text { Turning Rate } \\
\text { About Roll Axis }\end{array}$ & $>1.5^{\circ} / \mathrm{hr}$ & - $>35^{\circ}$ maneuver in $2 \mathrm{hrs}$ & - $63^{\circ} / \mathrm{hr}\left(.0175^{\circ} / \mathrm{sec}\right)$ \\
\hline $\begin{array}{l}\text { Effective Sail } \\
\text { Reflectance }\end{array}$ & $>0.75$ & - $92 \%$ over solar spectrum & - 85.9 \\
\hline $\begin{array}{l}\text { Anti-sunward } \\
\text { Emissivity }\end{array}$ & $>0.30$ & - 0.30 for $3-\mu$ film & - 0.40 \\
\hline $\begin{array}{l}\text { Membrane } \\
\text { Characteristics }\end{array}$ & $\begin{array}{l}\text { Space-durable, tear- } \\
\text { resistant, designed } \\
\text { for } 1 \mathrm{yr} \text { in the near- } \\
\text { GEO environment }\end{array}$ & $\begin{array}{l}-\sim 2-\mu \mathrm{CP} 1^{\mathrm{TM}} \text { with } 1,000 \mathrm{~A} \text { of } \\
\text { aluminum on front, bare CP1 } 1^{\mathrm{TM}} \text { on } \\
\text { back of sail. All materials have } \\
\text { space flight heritage. }\end{array}$ & $\begin{array}{l}\text { - } 2-\mu \text { Mylar }(\text { with 1,000 A of } \\
\text { aluminum on front and } 200 \mathrm{~A} \\
\text { blackened chromium on back }\end{array}$ \\
\hline $\begin{array}{l}\text { System } \\
\text { Flatness }\end{array}$ & $\begin{array}{l}\text { Effective for } \\
\text { propulsion }\end{array}$ & $\begin{array}{l}\text { 3-point quadrant support with } \\
\text { shear compliant border to insure a } \\
\text { flat sail, with a proper stress level } \\
\text { to obtain local flatness }\end{array}$ & - Stripped net loss $\sim 2 \%$ \\
\hline ACS & $\begin{array}{l}\text { 3-axis, minimize } \\
\text { propellant usage }\end{array}$ & $\begin{array}{l}\text { - Sliding trim control mass on truss } \\
\text { and tip bars to pinwheel quadrants } \\
\text { for roll. Micro PPT backup. }\end{array}$ & $\begin{array}{l}\text { - Totally propellantless using four } \\
\text { tip vanes }\end{array}$ \\
\hline
\end{tabular}

\subsection{Integrated Software Tools}

NASA developed a set of integrated simulation tools to predict the trajectory, maneuvers, and propulsive performance of a solar sail during a representative flight profile. ${ }^{[3]}$ The tools were designed to be integrated into an optimal guidance and navigational control (GNC) subsystem on a future flight mission. The tools incorporated the following analytical models:

- Solar radiation pressure acting on the sail as a function of sail orientation and distance from the Sun.

- Disturbance forces acting on the sail such as gravitational torques and thermal deformation of the support structure.

- Orbital mechanics.

- Sail structural dynamics. 
- Attitude control system dynamics.

- Navigational sensors.

\subsection{Optical Diagnostic System}

The overall objective for this task was the development of an Optical Diagnostic System (ODS) to

Technology Readiness Level (TRL) 6 for a solar sail. Possible requirements for the ODS included observation of the sail deployment and monitoring of the health and integrity of the sail during and after deployment. After solar sail deployment, the ODS would be available to provide shape and vibration measurements adequate to infer the stress state of the solar sail by aid of computational structural models, which could then feed real time into a closed loop spacecraft GNC system. The initial 6-month base period included concept development preceded by definition of the goals, priorities, and requirements for the ODS.

It was determined that continuous real-time integration with the guidance system was not necessary due to the quasi-steady-state nature of solar sail operations. In addition, studies showed the relative insensitivity of the thrust vector magnitude and direction to sail billow. ${ }^{[4]}$ The conceptual design process identified a number of significant challenges to on-orbit photogrammetry including significant weight, power, and data requirements for instruments and support structures for camera clusters, achieving sufficient image contrast, integrating targets into the sail membrane, and considerable software development needs. The concept development activities were conducted in parallel with the development of the ground test capability for the solar sail demonstrator hardware. A developmental test of a L'Garde inflatable boom in a thermal vacuum chamber at NASA Goddard Space Flight Center, as well as tests on smaller sail quadrants, provided an opportunity to familiarize researchers with cameras, analytical tools, and test operations. ${ }^{[5]}$

Building on this experience and adding capabilities for dynamic excitation and laser vibrometry, imaging, and a "truth" instrument, the ATK 10-m demonstrator testing was performed in the 16-m vacuum chamber at LaRC. These activities formed the foundation for the test methods and instrumentation employed in the final 20-m demonstrations tests. An exceptional team of photogrammetry experts from LaRC, working in conjunction with the contractor test teams, were successful in acquiring both static and dynamic deflection data in a number of various thermal and vacuum conditions and system configurations despite tremendous difficulties that arose. For example, condensate "rain" fell on the test article as the huge Plum Brook chamber was pumped down, causing boom tip positions to change so much that complex, remotely operated, adjustable instrument platforms had to be devised. A tremendous volume of data was required to provide high-resolution measurements over $400 \mathrm{~m}^{2}$ of area and data collection was made difficult by the clean aluminum walls and floor of the chamber which provide little natural contrast to the aluminized sails. The teams were constantly under the gun to debug problems, acquire data, and assess data quality quickly with limited hands on the equipment and only a few pump-downs allowed. The difficulty of photogrammetry was not insurmountable, but it did indicate the challenges identified in the conceptual design phase were real. Combined with a better understanding of the lack of a need for on-orbit photogrammetry, the further development of a flight system was not pursued.

\subsection{Advanced Computational Methods}

To address the concern that conventional finite element models might be inadequate to evaluate solar sails, a phased approach to address the structural design issue was pursued. They first relied on the prime contractors to apply standard practices using the existing state of the art. As part of the Ground System Demonstrations, LaRC, ATK, and L'Garde created Finite Element Models (FEAs) of the 10-m systems using both commercial off-theshelf (COTS) and custom software. These models did not always converge and were computationally intensive, but no more so than is experienced in typical spacecraft design. The purpose of this task was to create methods/algorithms/techniques that improved the conventional FEA of the membranes, booms, and other subsystems. Several methods were identified, but the option phases to complete and validate them were not funded due to the success of the prime contractors in modeling the 20 -m systems with conventional techniques, thus lowering the priority of this task below the level of the available funding.

\subsection{Structural Analysis and Synthesis Tools}

This task also addressed the structural analysis issue by developing from the ground-up new and unconventional modeling techniques. Techniques considered included Direct Transfer Function Modeling 
(DTFM) and Parameter Variation Processing (PVP). The overall objectives for this task were completion of DTFM modeling/analysis methods for long booms, completion of capability to evaluate effects of imperfections, completion of PVP method for analyzing wrinkled membranes, and completion of test/analysis correlation by using existing test data. As in the above task, this effort was terminated prior to completion due to success using conventional modeling methods with the 20 -m systems and a lack of funding.

\subsection{Lightweight Attitude Control System}

The objectives of this task were: (1) to design, integrate, and test a sail attitude control system (SACS) employing a two-axis gimbaled control boom, and (2) to develop a high-fidelity, multi-flexible body model of ATK's solar sail for the purpose of validating a thrust vector control (TVC) concept employing a two-axis gimbaled control boom. One of the major findings from this study was that the two-axis gimbaled control boom was not a mass efficient method of controlling a sail. A more efficient method was derived based on an offset mass moved along the booms by a clothesline-like apparatus to control pitch and yaw and rotating stabilizer bars at the sail tips to pinwheel the sail quadrants for roll control. This finding led to a major redesign of the ATK 20$\mathrm{m}$ hardware to accommodate the new TVC concept. An attitude determination and control block diagram were derived to present the application/integration of the inertial stellar compass with a range of ACS options from $\mathrm{cp} / \mathrm{cm}$ offset to pulsed plasma microthrusters. ${ }^{[6]}$

\subsection{Characterization of Candidate Solar Sail Materials}

The purpose of this task was to conduct laboratory characterization of several candidate solar sail materials. The space radiation and micrometeoroid environments for 1.0 and 0.5 astronomical units missions were defined and candidate materials were tested against these radiation and meteoroid environments. Through a series of learning tests, the sample hold-down design was optimized and a flexure test developed. Several samples of the SRS and L'Garde membrane materials were tested by subjecting them to gigarad levels of radiation in simulations of long duration solar wind mission type. ${ }^{[7]}$ While some of the samples showed significant levels of degradation in mechanical strength, solar sail loading is so low, very little strength is needed.

\subsection{Advanced Manufacturing Technologies}

The purpose of this task was to investigate and develop an integrated approach to ultrathin film solar sail manufacturing. The focus was on improving coating processes and technologies; developing sail seaming technologies for large monolithic sails; providing an integrated approach to membrane coating, acceptance, assembly and integration; and integrating future improvements into the process such as electrospun nanofibers for ripstop enhancement without added mass and the addition of carbon black nanotubes to the sail backside to increase emissivity. The final results of this 2-year effort are the development of a scroll coating system, the development of coating capabilities of less than $2.5 \mu$, and the development of a membrane seaming system able to form monolithic sails with coatings at least as thin as $2.5 \mu$.

\subsection{Smart Adaptive Structures}

In order to mature the TRL of solar sail propulsion, advancements must be made in the pointing and dynamical control of these large space structures. This tasks' objective was to develop and verify structural analytical models, develop structural scaling laws and develop adaptive control laws for solar sails to be verified on a >30-m vertically supported boom.

\subsection{Sail Charging}

Due to two extreme characteristics of future solar sail missions, the large surface area of the sail and the long duration of potential missions, typical spacecraft charging issues will be exacerbated. The purpose of this task was to characterize charged particle environments for analyzing solar sail charging in the solar wind and at geostationary orbit and to model surface and internal electric fields and potentials for solar sails using existing spacecraft charging models. Solar sail materials were tested in simulated charging environments to determine permeability and charge retention properties. A significant finding was that there will be little charging of the sail surfaces, $\sim 10 \mathrm{v}$ as a worst case in sunlight. The study found that problems arise if the sail material backing is nonconductive or electrically decoupled from the front surface. In that case, the shadowed back surface can reach 
potentials of -30 to $-40 \mathrm{v}$ relative to the space plasma in the solar wind on the order of arcing onset potentials. The solution is to make sure the sail material is conductive front to back and end-to-end if the sail is to be in geosynchronous orbit or in the auroral zone and be careful with electrically isolated objects in the shadow of the sail.

\subsection{Long-Term Space Environmental Effects}

Critical to the development of solar sails is an investigation of space environmental effects on these large thin film materials and the edge support technologies. This task was related to the "Characterization Solar Sail Materials" task above. The above task used accelerated dose levels over a shorter period of time to simulate the total dose of radiation received by a material for many years. The purpose of this task is to provide critical thermal, optical, mechanical, and surface data on large sails taking into account edge stresses and edge support technologies that can only be characterized using large size sails but not at accelerated levels. These resulting test data could be used to validate the accelerated dose test methodology regarding the durability of candidate sail material (embrittlement, optical, mechanical, surface, and thermal properties).

\section{SMALL SOLAR SAIL SYSTEM-LEVEL DEVELOPMENT}

\subsection{NanoSail-D Overview}

NASA MSFC has recently been investigating the application of solar sails for small satellite propulsion. Likewise, the NASA Ames Research Center (ARC) has been developing small spacecraft missions that have a need for a mass-efficient means of satisfying de-orbit requirements. Hence a synergistic collaboration was established between these two NASA field centers with the objective of conducting a flight demonstration of solar sail technologies for small satellites in a project called "NanoSail-Deorbit" or "NanoSail-D."

The original NanoSail-D mission flew onboard the ill-fated Falcon-1 Rocket launched August 2, 2008 and, due to the failure of that rocket, never achieved orbit. The NanoSail-D flight spare will be flown in the Fall of 2010. Both the original sailcraft and the flight spare are hereafter referred to as "NanoSail-D." The sailcraft consists of a sail subsystem stowed in a 3-element CubeSat. Shortly after deployment of the NanoSail-D, the solar sail will deploy and mission operations will commence. This demonstration flight has two primary technical objectives: (1) to successfully stow and deploy the sail and (2) to demonstrate deorbit functionality. ${ }^{[8]}$ Passive attitude stabilization of the spacecraft will be achieved using permanent magnets to detumble and orient the body with the magnetic field lines and then rely on atmospheric drag to passively stabilize the sailcraft in an essentially maximum drag attitude.

\subsection{NanoSail-D Design}

The stowed configuration of the NanoSail-D spacecraft is illustrated in Figure 2. The spacecraft bus, provided by ARC, is configured with a flight-proven computer, power supply, S-band radio and UHF beacon radio. Permanent bar magnets that are installed in the bus closeout panels provided passive attitude control. The spacecraft bus occupies the upper 1/3 volume of the 3-U sized "CubeSat" class spacecraft.

The solar sail subsystem occupies the lower $2 / 3$ volume of the spacecraft. Sail closeout panels provide protection for the sail and booms during the launch phase of the mission. These panels have spring-loaded hinges that will be released on-orbit, under the command of the spacecraft bus. Figure 3 shows the fully deployed NanoSail-D in a ground test.

The ManTech SRS sail subsystem was divided into two primary components - the sail assembly and the boom mechanical assembly. Once assembled, the sail subassembly consisted of a standalone unit that bolted to the bus and connected to the release electronics. Launch operations consist of a simple, timed two-actuation system. The initiating event consists of a burn-wire release of the door panels. The door panels protect the sail material and help to constrain it for the launch environment and ascent venting. The sail membranes, fabricated from aluminum coated CP1 $1^{\mathrm{TM}}$ material used originally in the ATK Solar Sail Ground Demonstration Project described above, are z-folded and rolled onto a sail spool. The Trac booms, developed by the U.S. Air Force Research Laboratory, are also rolled onto a boom spool. The stored strain energy of the rolled booms provides the driving force to simultaneously deploy both the booms and the sail quadrants. 


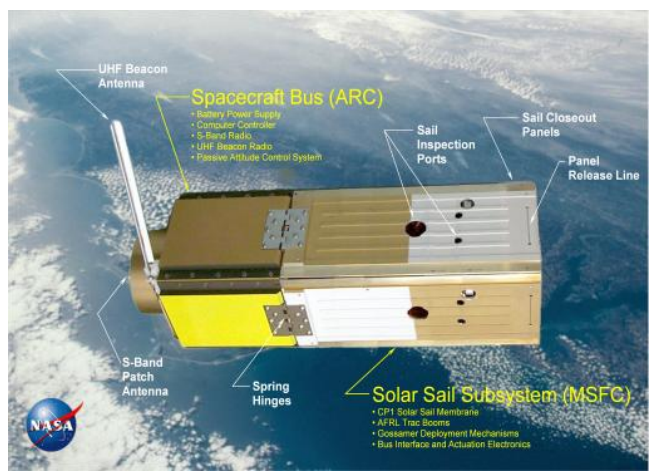

Figure 2. On-orbit view of the spacecraft before sail deployment.

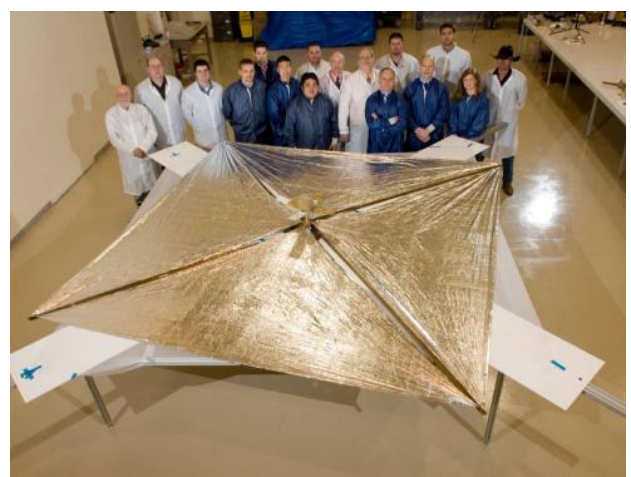

Figure 3. NanoSail-D ground deployment test.

Mission data was to be comprised by radar cross-sectional area data, optical images, and orbital elements. Radar cross-sectional area data and optical images were to be obtained by the U.S. Army's Reagan Test Site. This data would enable estimation of a lower bound on deployed sail area (lower bound only because the sail plane was likely not be normal to the line of sight during data acquisition and hence the projected area normal to the line of sight was to be measured). Estimation of the deployed area will be difficult during initial phases of the mission when the sail is to be "tumbling" about the Earth's magnetic field lines during part of the orbit and passively stabilized in the maximum drag orientation near perigee. Hence the estimation of deployed area from orbit data will depend on the latter phases of the mission when the orbit circularizes and the sail passively stabilizes due to aerodynamic torque in a relatively constant local vertical/local horizontal (LVLH) attitude. In the event that the sail does not stabilize prior to re-entry, orbital analysis would have allowed an estimation of an average ballistic coefficient that could have been correlated to an average area.

The NanoSail-D flight spare is scheduled to launch in the Fall of 2010.

\subsection{THE FUTURE OF SOLAR SAILS IN NASA}

NASA is not currently funding solar sail technology. However, NASA is now preparing for a dramatic change in focus toward the development of advanced space technology that will enable new human and robotic exploration of the solar system. Solar sails are a technology that can support this aim, and it is likely that within the next few years NASA will again be aggressively advancing the technology toward mission implementation.

\section{REFERENCES}

1. D. Murphy, "Validation of A Scalable Solar Sailcraft," 53rd JANNAF Propulsion Meeting, December 2005.

2. D. Lichodziejewski, et al., "Vacuum Deployment and Testing of a 20-m Solar Sail System," 47th AIAA/ASME/ASCE/AHS/ASC Structures, Structural Dynamics, and Materials Conference, May 2006, AIAA 2006-1705.

3. J. Ellis, et al., "A Solar Sail Integrated Simulation Toolkit," Proc. AAS/AISS Spaceflight Mechanics, Maui, HI, Feb., 2004, AAS 04-283.

4. A. Ewing, "Solar Sail Propulsion Sensitivity to Membrane Shape and Optical Properties Using the Solar Vectoring Evaluation Tool (SVET)," 53rd JANNAF Propulsion Meeting, December 2005.

5. R. Pappa, et al., "Optical Diagnostic System for Solar Sails: Phase 1 Final Report," NASA/TM-2004213511, Dec. 2004.

6. S. Thomas, M. Paluszek, B. Wie, D. Murphy, "AOCS Performance and Stability Validation for a 160-m Solar Sail with Control-Structure Interactions," 41st AIAA Joint Propulsion Conference, July 2005, AIAA 20053926.

7. D. Edwards, et al., "Characterization of Candidate Solar Sail Material Exposed to Space Environmental Effects," 42nd AIAA Aerospace Sciences Meeting and Exhibit, Jan. 2004, AIAA 2004-1085.

8. Peter C. E. Roberts and Patrick G. Harkness, "Drag Sail for End-of-Life Disposal from Low Earth Orbit," Journal of Spacecraft and Rockets, Vol. 44, No. 6, Nov.-Dec. 2007 
Status of Solar Sail Technology Within NASA

1 تs Johnson

DEF Jjty Manager, Advanced Concepts Office NASA George C. Marshall Space Flight Center 


\section{Solar Sail Propulsion Technology Status}
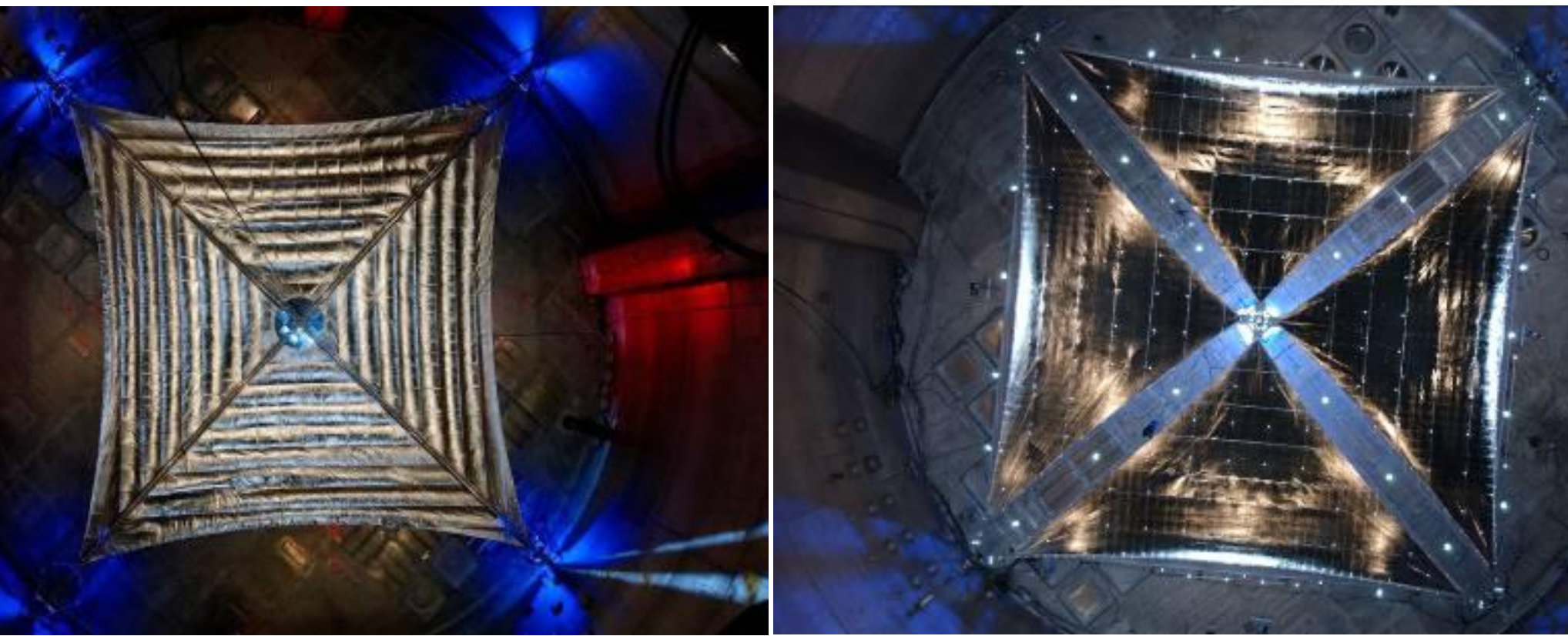

- Technology Area Status:

- Two competing teams designed, fabricated, and tested solar sails and performed system level ground demonstrations:

- $10 \mathrm{~m}$ system ground demonstrators were developed and tested in 2004.

- $20 \mathrm{~m}$ system ground demonstrators designed, fabricated, and tested under thermal vacuum conditions in 2005.

- Developed and tested high-fidelity computational models, tools, and diagnostics.

- Multiple efforts completed: materials evaluation, optical properties, long-term environmental effects, charging issues, and assessment of smart adaptive structures. 


\section{ATK Solar Sail Development}

- PI: David Murphy, ATK Space Systems

- Technical Team:

- ATK (Goleta, CA) systems engineering \& coilable booms

- Man Tech (Huntsville, AL): Sail manufacture \& assembly

- LaRC (Hampton, VA) Sail Modeling \& Testing

- MSFC (Huntsville, AL) Materials Testing

- Overall Strategy

- Leveraged ST 7 Phase A Design

- Improve performance with Ultra-Light Graphite Coilable booms

- Synergy with SailMast Testbed selected to fly on ST8

- Sail membrane, AL coated $2.5 \mu \mathrm{m}$ CP1, compliant border, 3 point attach

- Thrust Vector Control uses sliding masses along boom with spreader bars and micro-PPT at mast tip
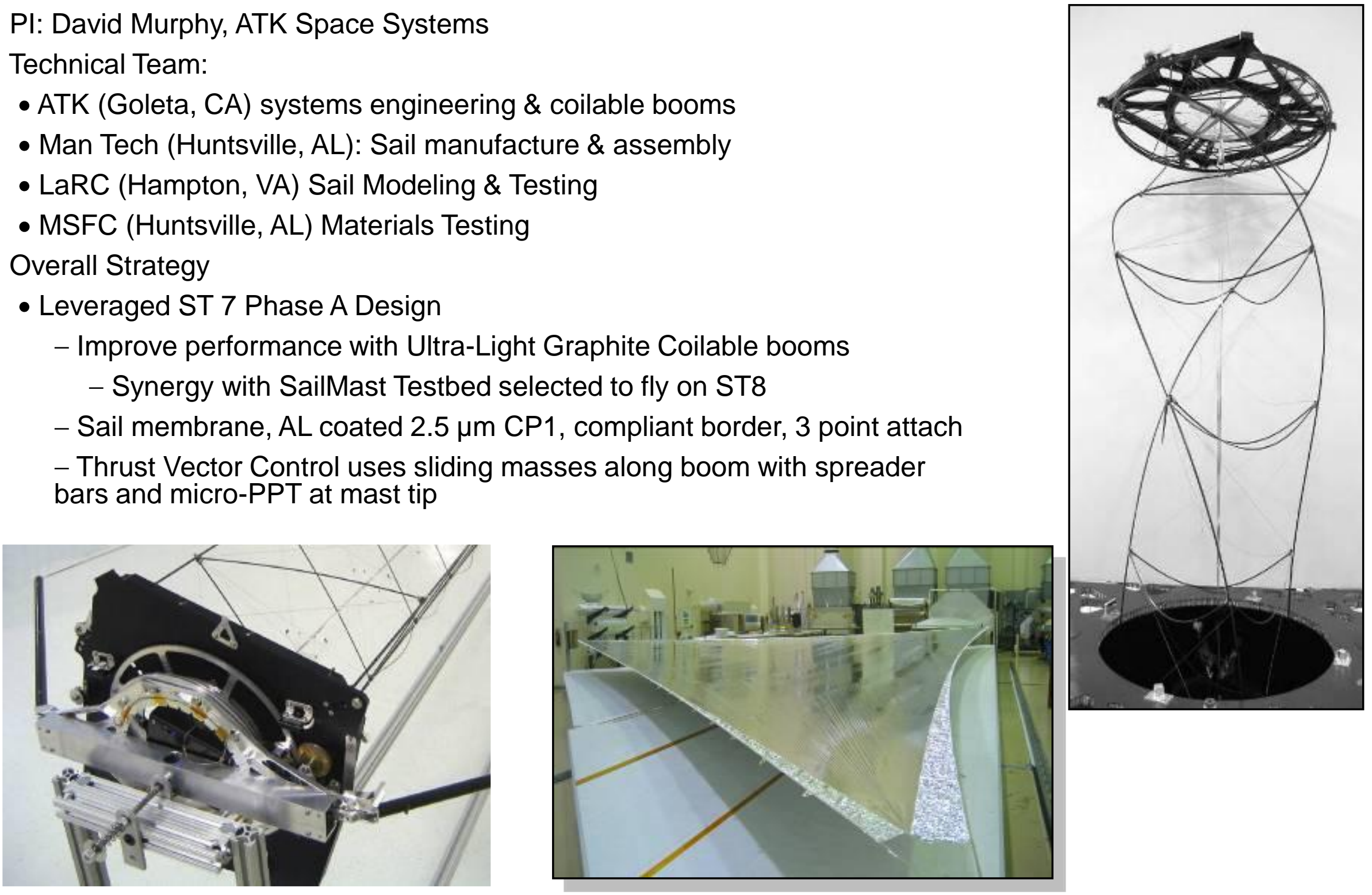


\section{ATK Solar Sail Development, Continued}

- Operating Temperature $>16^{\circ} \mathrm{C}$ at .98 au

$\checkmark$ First Natural Frequency $>0.02 \mathrm{~Hz}$

- Stowed Package $>1.5 \mathrm{~m}$ dia. by $0.53 \mathrm{~m}$

- System Mass:

$>108 \mathrm{~kg}(\mathrm{w} /$ contingency)

- Characteristic acceleration

$>0.76 \mathrm{~mm} / \mathrm{s}^{2}$

$>0.34 \mathrm{~mm} / \mathrm{s}^{2}$ with $130 \mathrm{~kg} \mathrm{SC}$

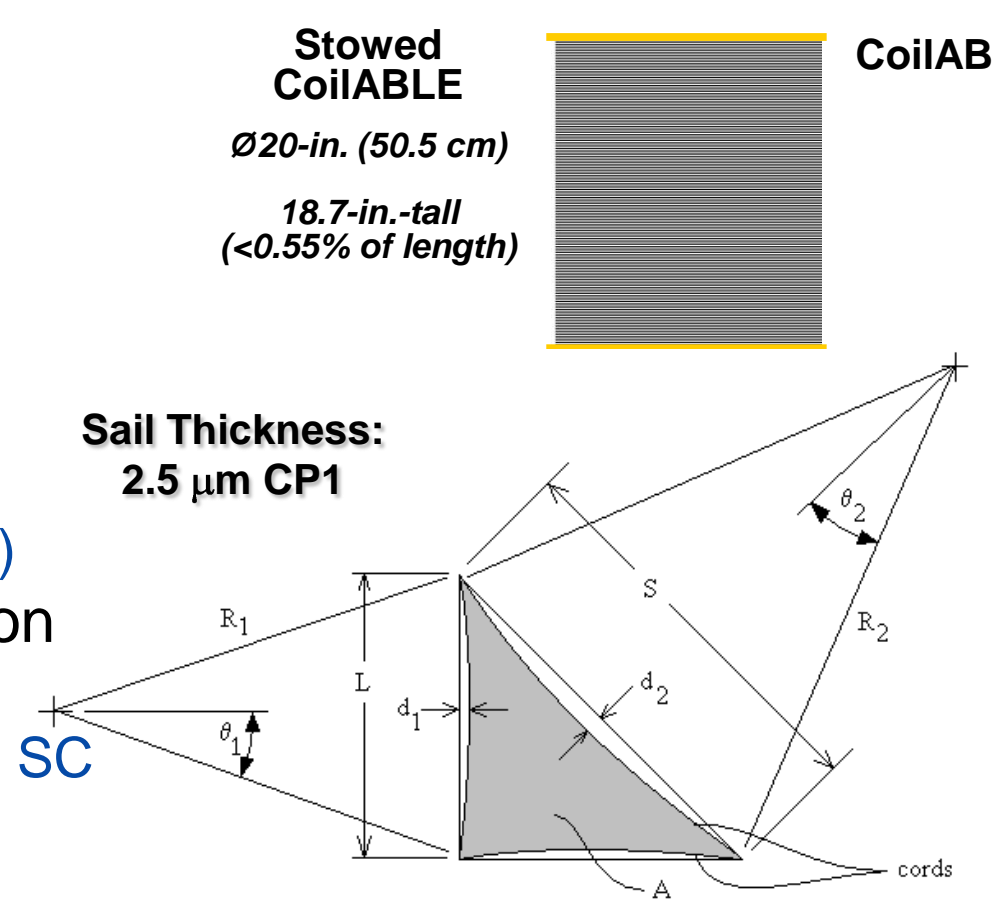

Stowed

ø20-in. $(50.5 \mathrm{~cm})$

18.7-in.-tal

$<0.55 \%$ of length

(

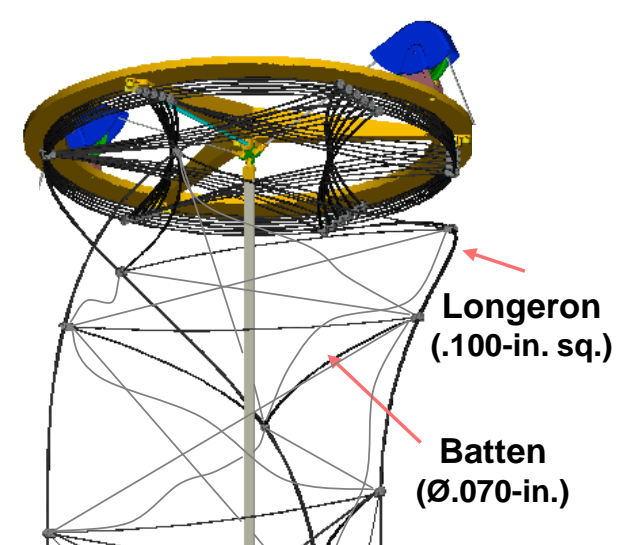

Cut-Away of Stowed Package

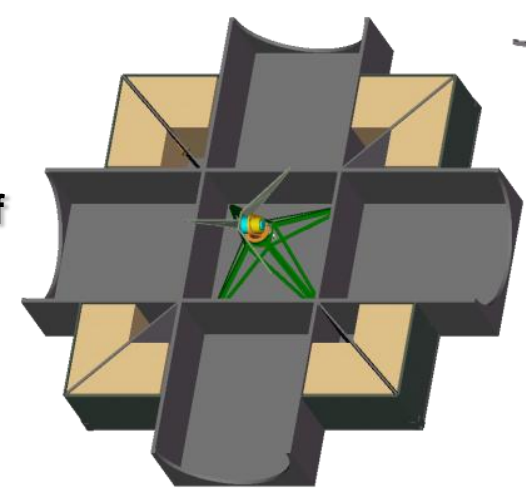




\section{ManTech Solar Sail Membrane Features}

Membrane Design:

4-quadrant planar sail

- Compliant Border interface between edge cable and membrane

- Shear insensitive, Cord/Material CTE mismatch insensitive

- Thermal Gradient insensitive

\section{Sail Material: $\quad$ CP1 Polyimide}

- High Operating Temperature $\left(>200^{\circ} \mathrm{C}\right)$

- UV Stable

- Essentially Inert

- Soluble (Wet Process), modifiable with variety additives improve conductivity and thermal properties

- 2.5 micron polyimide

- Flight Proven --- flying on Numerous GEOCOM satellites

\section{Sail Construction Methods:}

A gossamer film construction similar to gusseted, reflective blankets flying on numerous GEOCOM satellites

- Scalable Construction Methods --- current system $>20 \mathrm{~m}$

- Adhesive less Bonding Methods --- eliminates sticking and contamination risks.
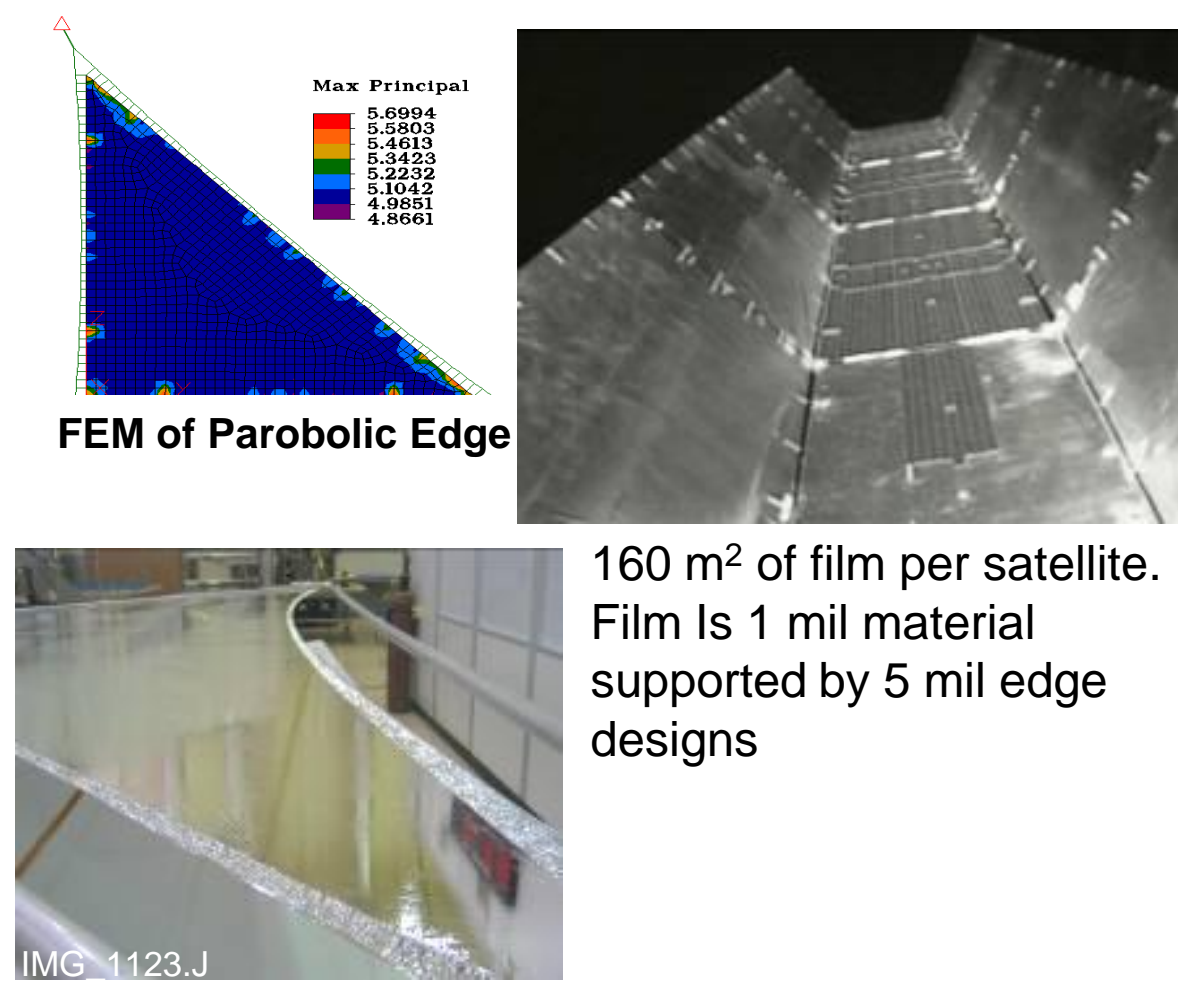

$160 \mathrm{~m}^{2}$ of film per satellite. Film Is 1 mil material supported by 5 mil edge designs

\section{Sail with Compliant Border}

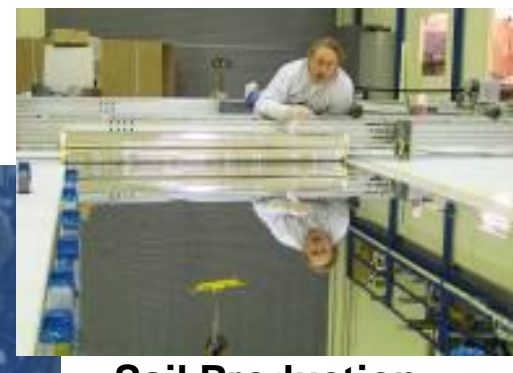

Sail Production 


\section{ATK 20-m System Ground Demonstrator}
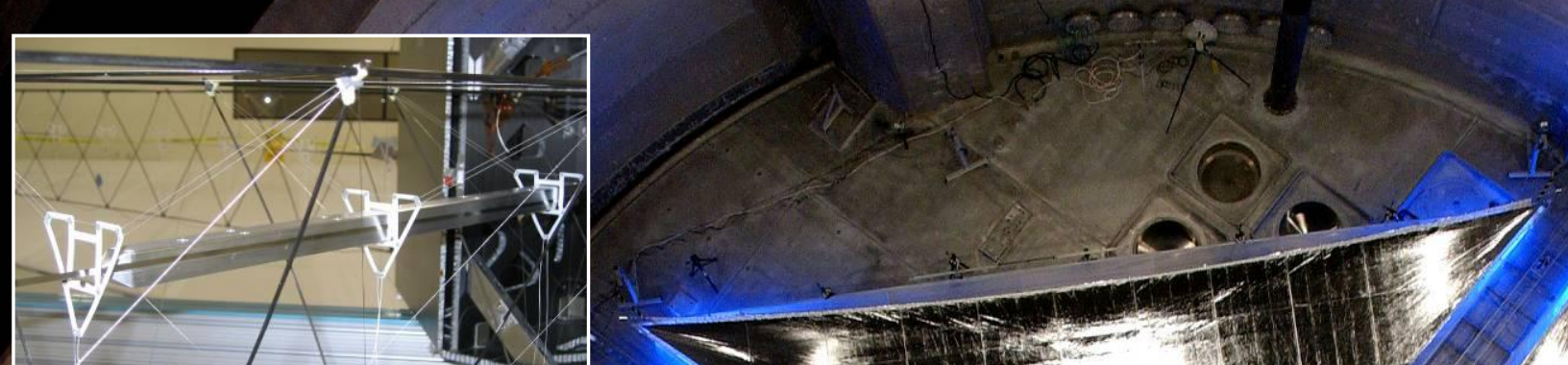

Translating Mass

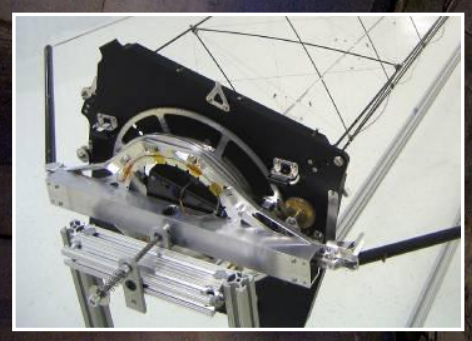

Spreader Bar

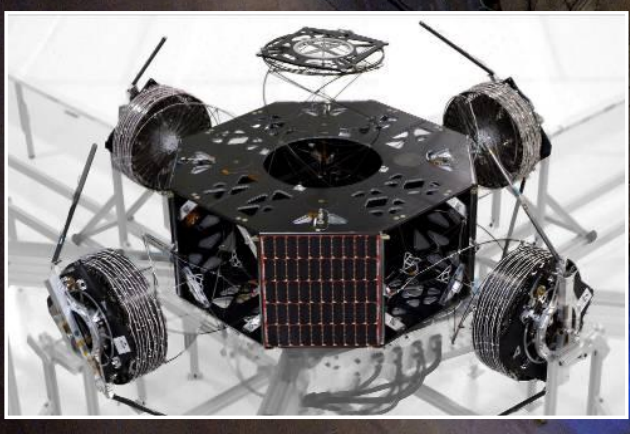

Central Structure

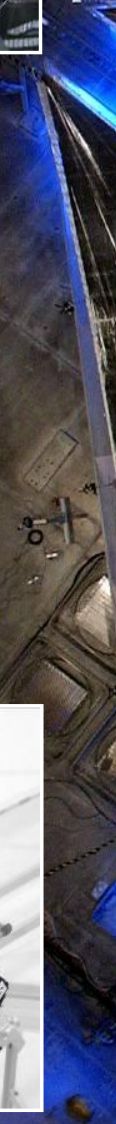

Q
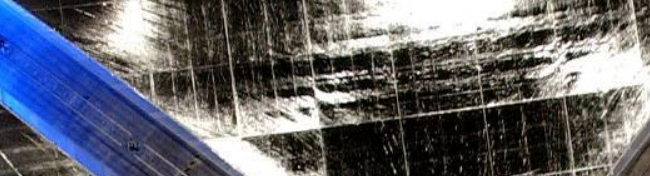

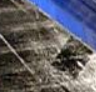
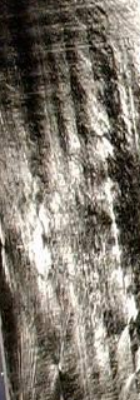
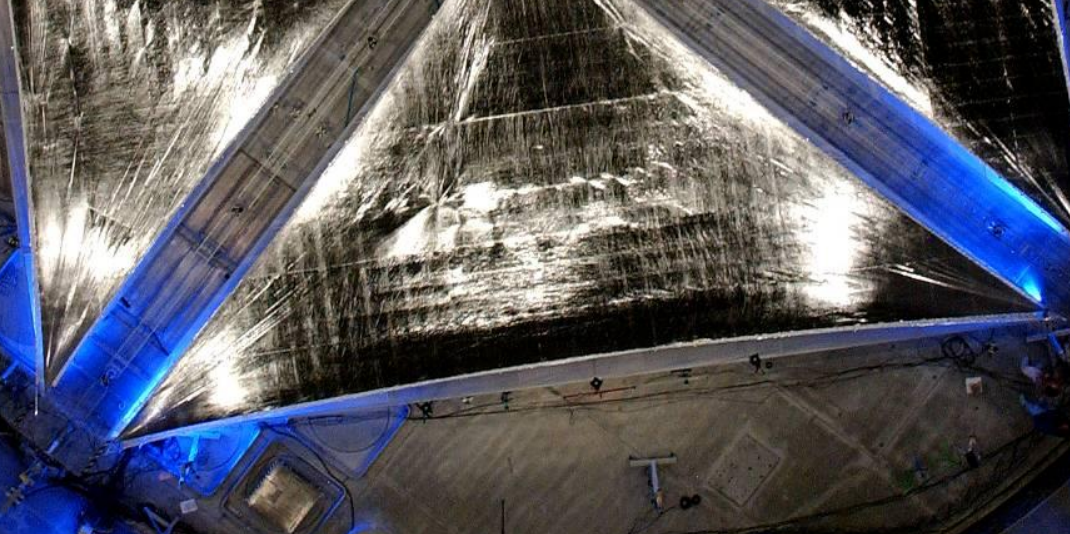

ATK 20-M SGD

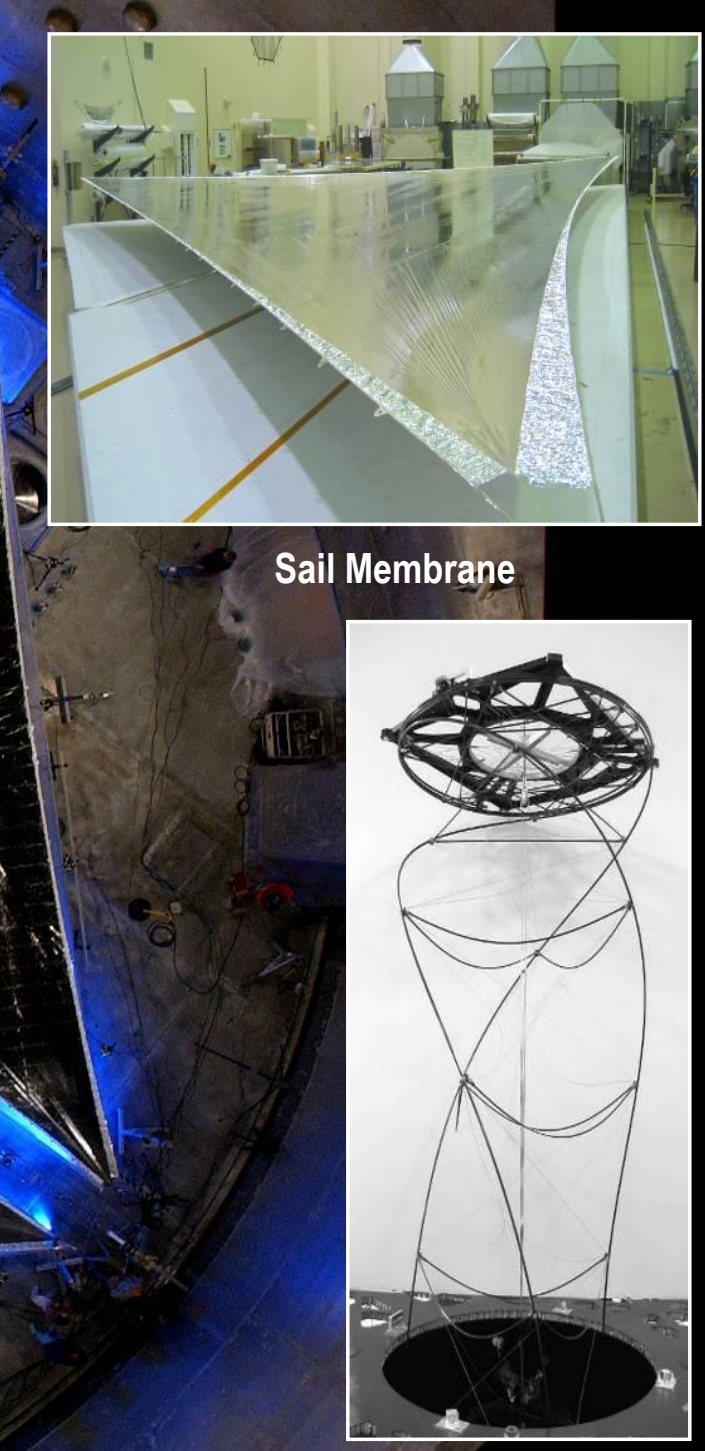

CoilABLE Masts 


\section{L'Garde Solar Sail Development}

- PI: David (Leo) Lichodziejewski, L'Garde, Inc.

- Technical Team:

- L'Garde, Inc. (Tustin, CA) systems engineering and inflatable truss

- Ball Aerospace \& Tech Corp. (Boulder, CO) mission eng. \& bus design

- LaRC (Hampton, VA) sail modeling \& testing

- JPL (Pasadena, CA) mission planning \& space hazards

- Overall Strategy

- Concept Leveraged ST-5 Phase A and Team Encounter experience

- Sail membrane, AL coated $2 \mu \mathrm{m}$ Mylar attached with stripped net

- Lightweight Boom With Sub-Tg Rigidization

- 4 Vane Thrust Vector Control
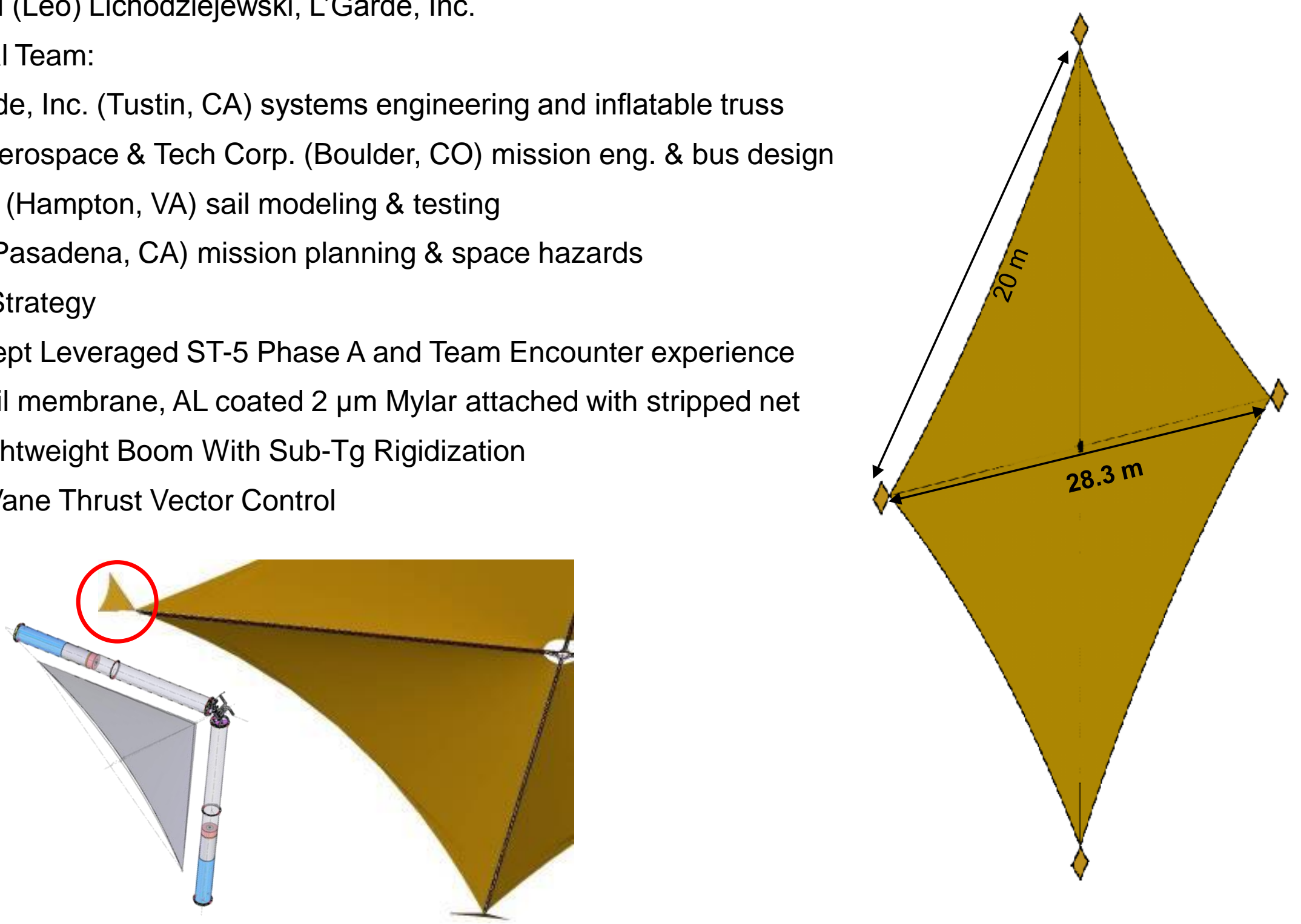


\section{Beam Characteristics}
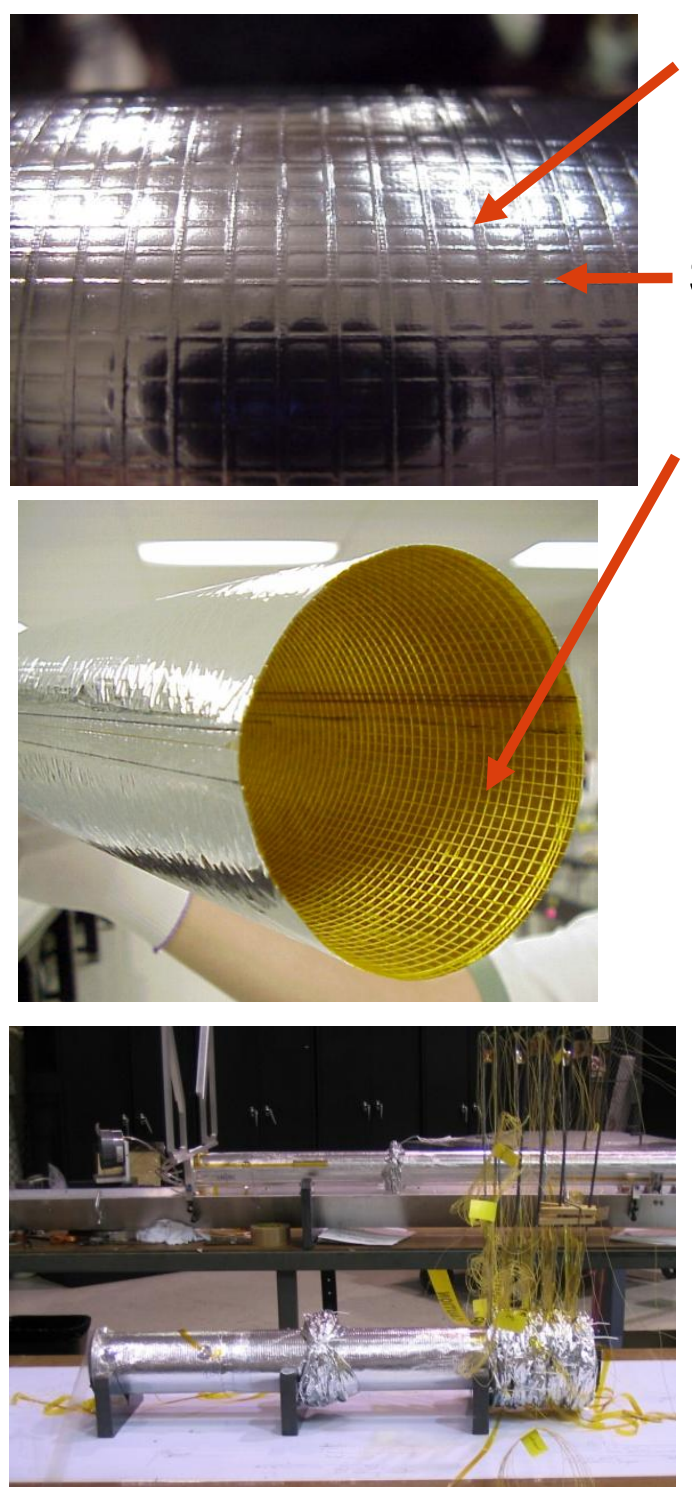

Stowed $7 \mathrm{~m}$ boom ( .5 $\mathrm{m})$
Load bearing longitudinal uni-directional fibers

- Fibers impregnated with resin (rigid below $-20^{\circ} \mathrm{C}$ )

- $0.48 \mathrm{AU}$ design requires greater fiber density to withstand loads from the increased solar flux

Spiral wrap

- Stabilizes longitudinal fibers

- Allows over-pressurization for deployment anomalies Bonded Kapton bladder and Mylar

- Encapsulation "skin" carries shear

- Aircraft fuselage like structure

Beam Structure

- Sail structure is stressed for solar loading in one direction for mass efficiency

- Truss system comprised of mostly tension elements, minimal rigid components

- Highly mass efficient, 36g/m linear density

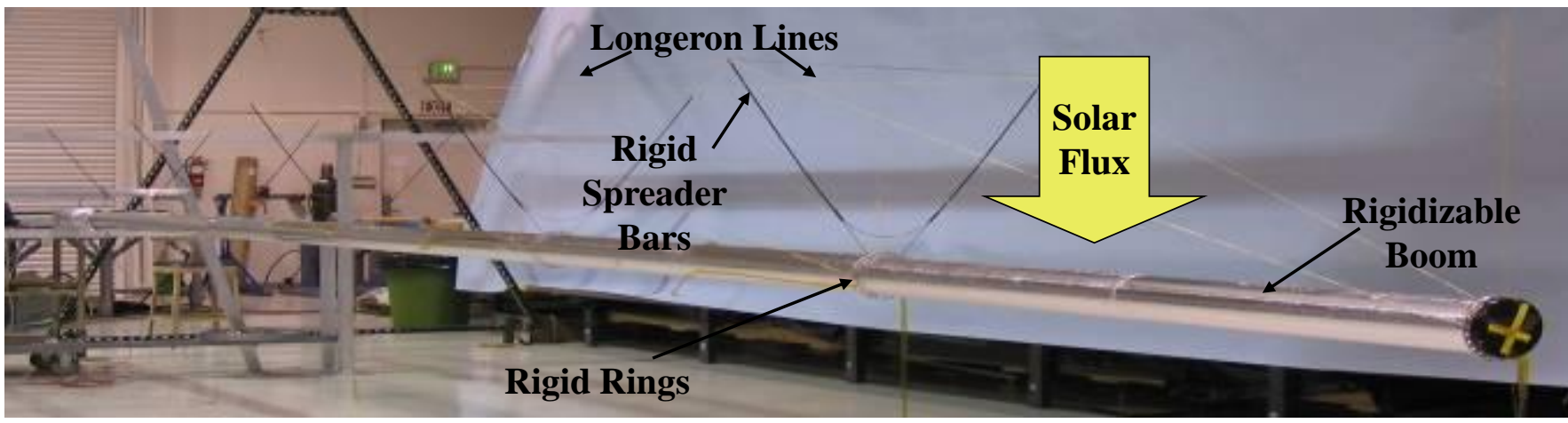

Deployed $7 \mathrm{~m}$ boom 


\section{Net/Membrane Sail}

Chords are suspended from the boom rings

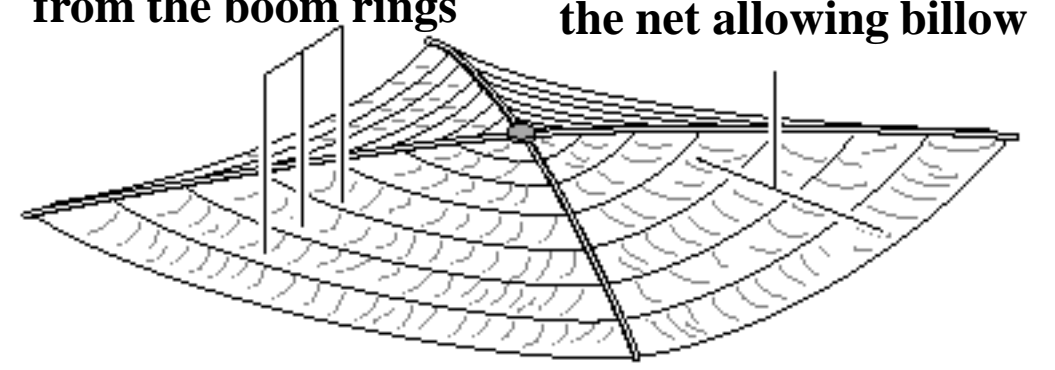

Net/Membrane Sail Schematic

Sail material is laid over the net allowing billow

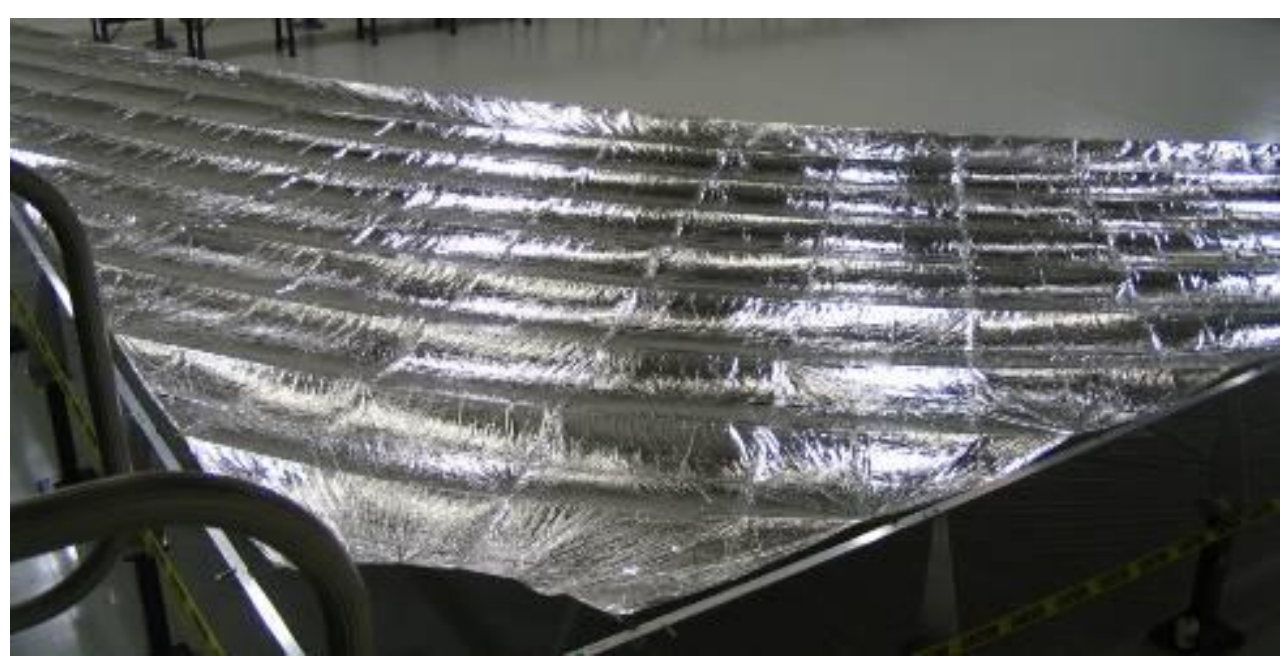

20m Sail Quadrant

\section{Net Membrane}

- Sail is supported by a low CTE net with additional membrane material added to allow for thermal compliance

- Sail properties effect local billow between net members only, global sail shape is stable

\section{Advantages}

- Net defines the overall sail shape, not the membrane

- Stability and geometry of the sail is effectively decoupled from membrane properties

- Sail shape, and hence thrust vector, sailcraft stability and performance, are predictable and stable

- No high local stress concentrations in the sail, loads are transferred though the net, not the membrane

- Very scalable, larger net/membrane sails simply add additional net elements to control overall shape

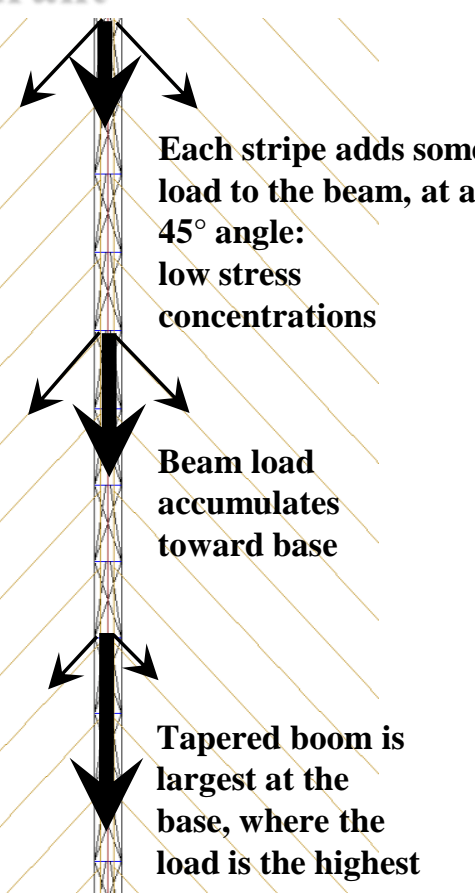




\section{L'Garde 20-m System Ground Demonstrator (SGD)}

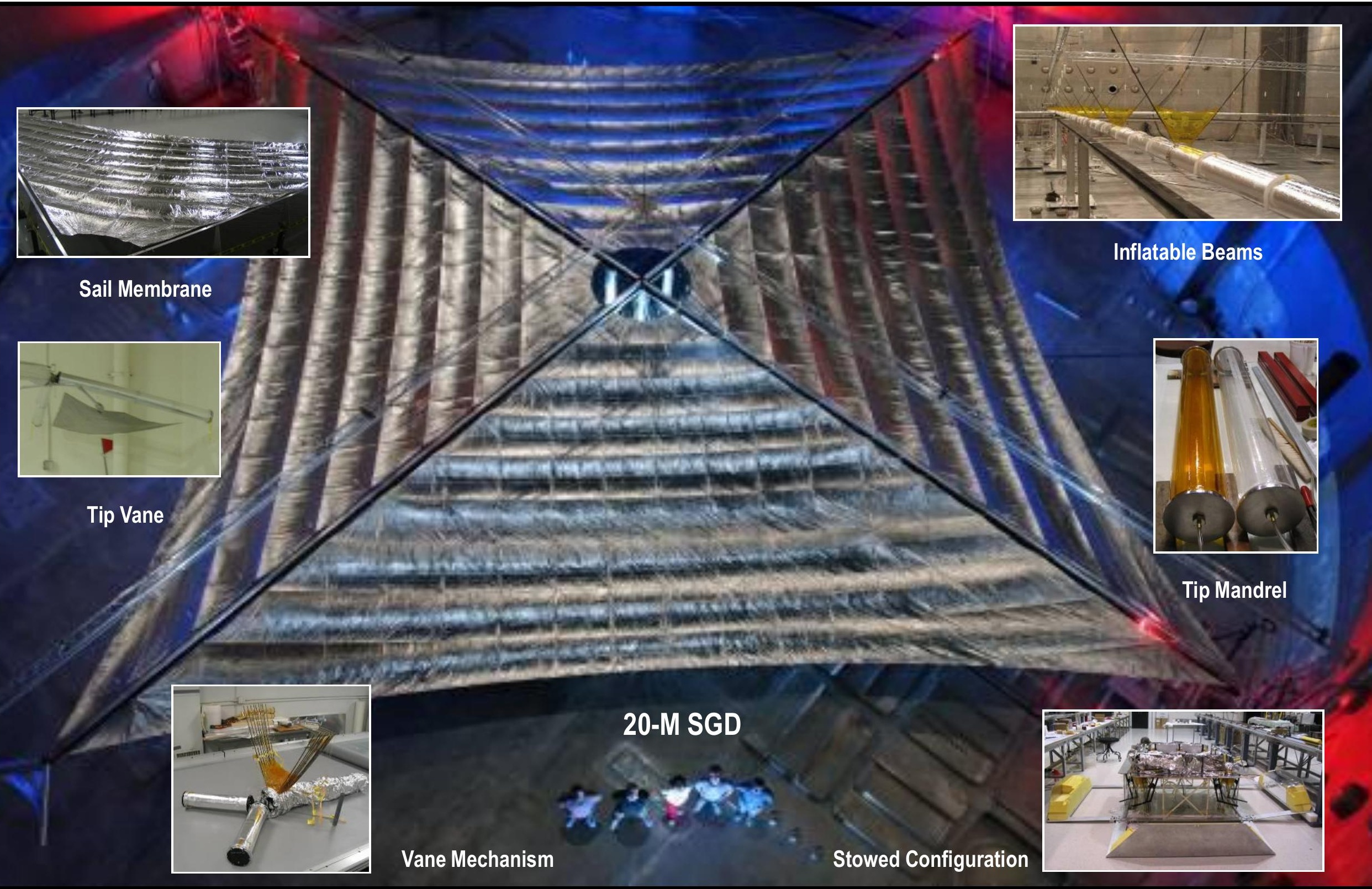




\section{Solar Sail Subsystem Development}
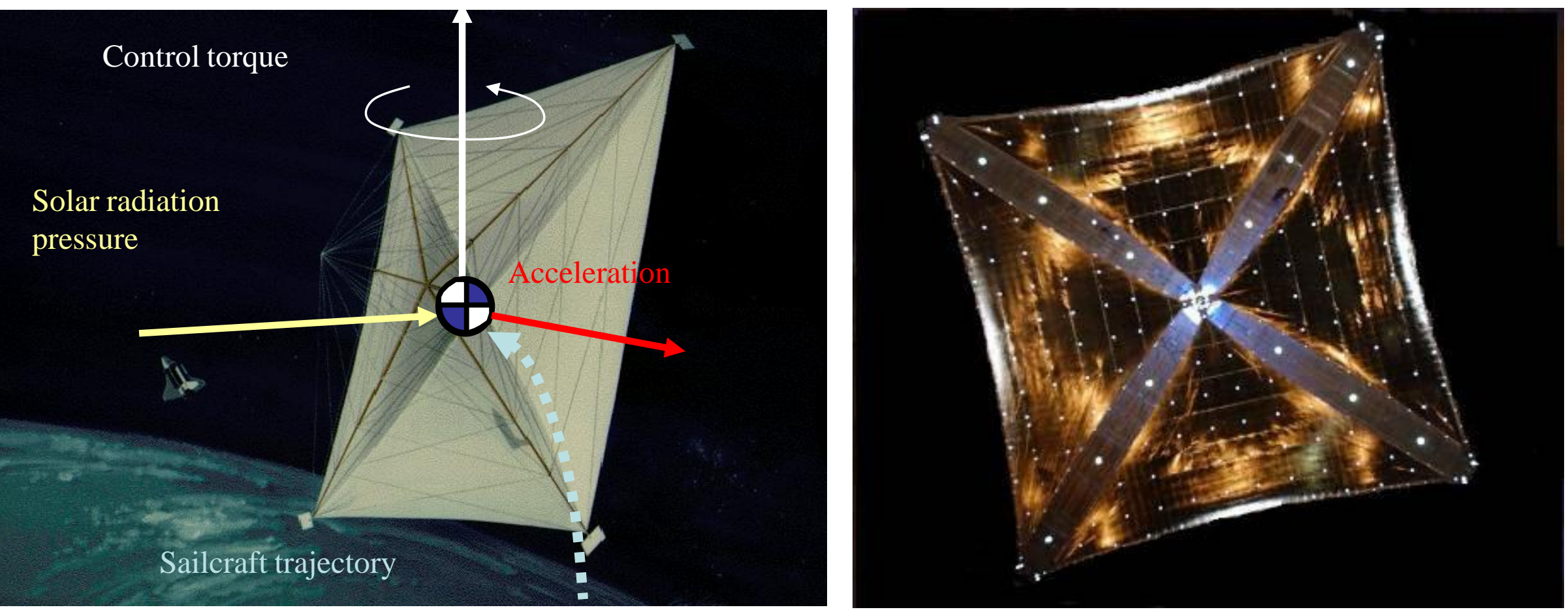

\section{Solar Sail Spaceflight Simulation}

Software (S5)

Developed an integrated simulation and analysis software tool for optimal design of solar sail trajectories and for evaluation of guidance navigation and control strategies.
Optical Diagnostic System (ODS) Developed a lightweight integrated instrumentation package to allow measurement of sail shape, tension and temperature; boom \& sail vibration modes and stress; and deployment monitoring. 


\section{Solar Sail Subsystem Development- cont.}

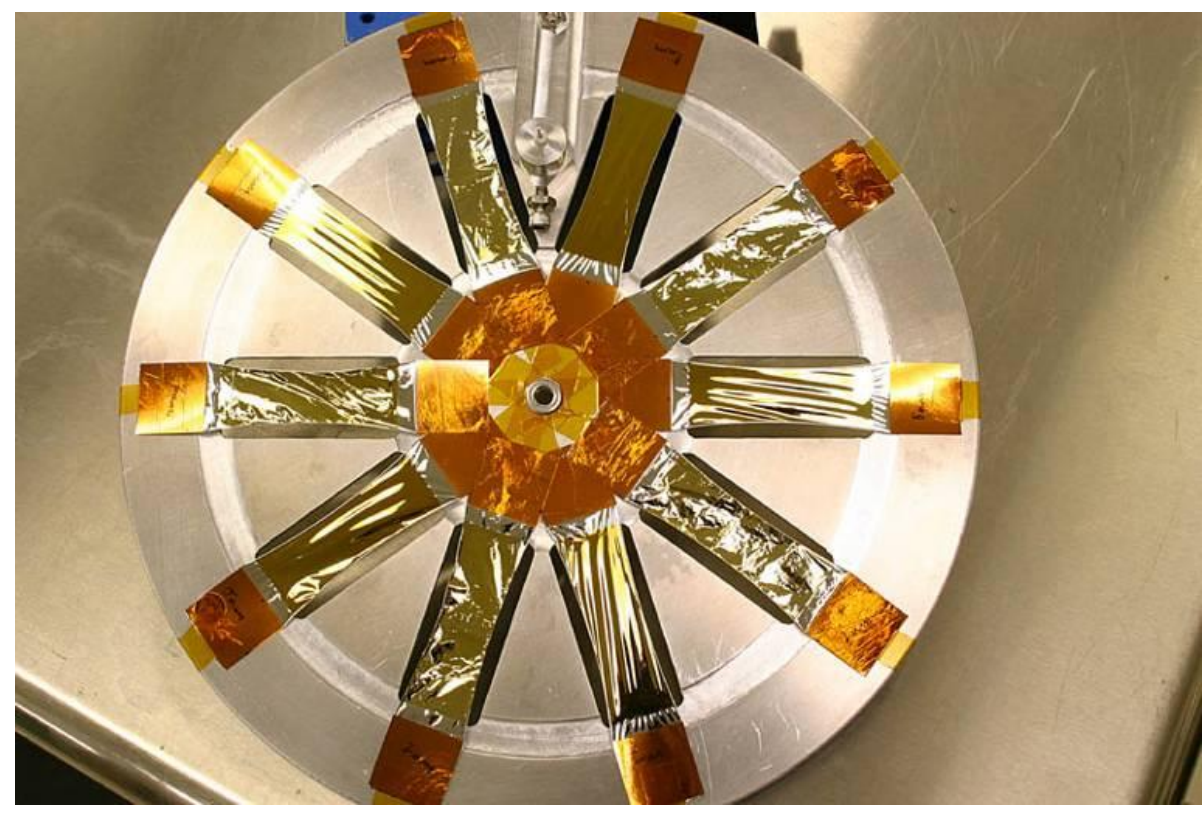

Samples prior to UV exposure

Material Testing

Characterized engineering performance of candidate SS materials at .5 and $1 \mathrm{AU}$, gauging material property tolerances after exposure to simulated missionspecific charged-particle and micrometeoroid environments.
Able's Solar Sail Mast with a Trim Control Mass (TCM), Roll Spreader Bars (RSBs), and microPPTs

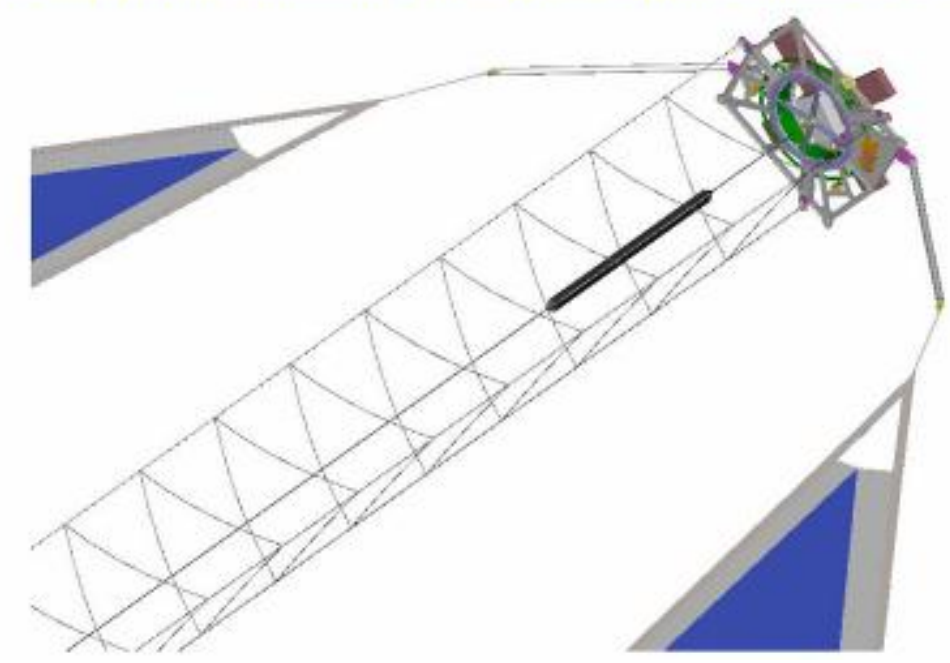

Development of a Lightweight Robust SACS and a Software Toolkit for Solar Sails

Developed of a highly integrated, low cost, low mass, low volume, and low power attitude determination and control system and develop a high-fidelity multibody modeling and simulation software toolkit. 


\section{Solar Sail Subsystem Development- cont.}

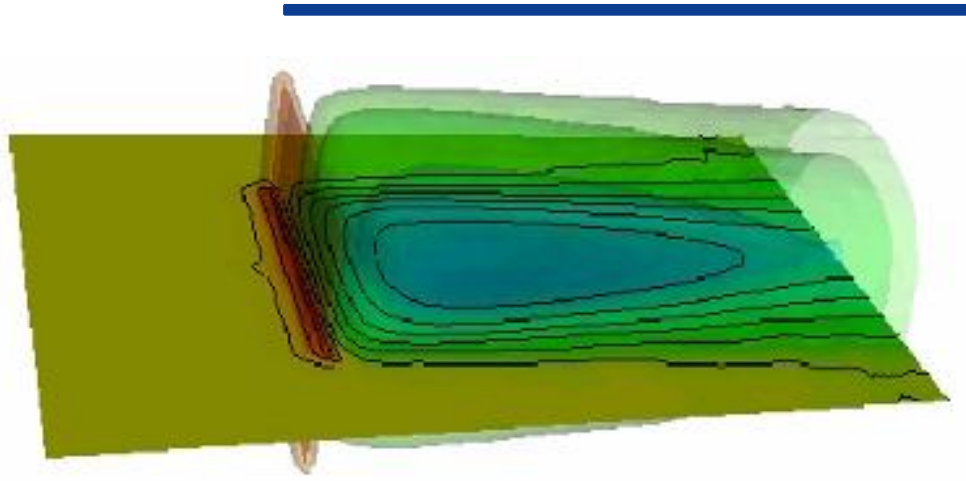

Plasma Flow Model of sail in the solar wind with the potentials normalized by $0.25 \mathrm{Te}$

Sail Charging Analysis

Developed environmental and sail configuration models and design guideline criteria for solar sails. Conduct laboratory assessment of potential for destructive charging fields and arcing events within the sail and surrounding environment.

Advanced Manufacturing Technologies Developed and refine the technology of sail assembly for manufacturing large monolithic sails, improving membrane coating processes and technologies
Smart Adaptive

Structures

Identified nonlinear mechanism for existing $\mathbf{4 0}$ meter coilable boom. Assess potential for control structures interactions.

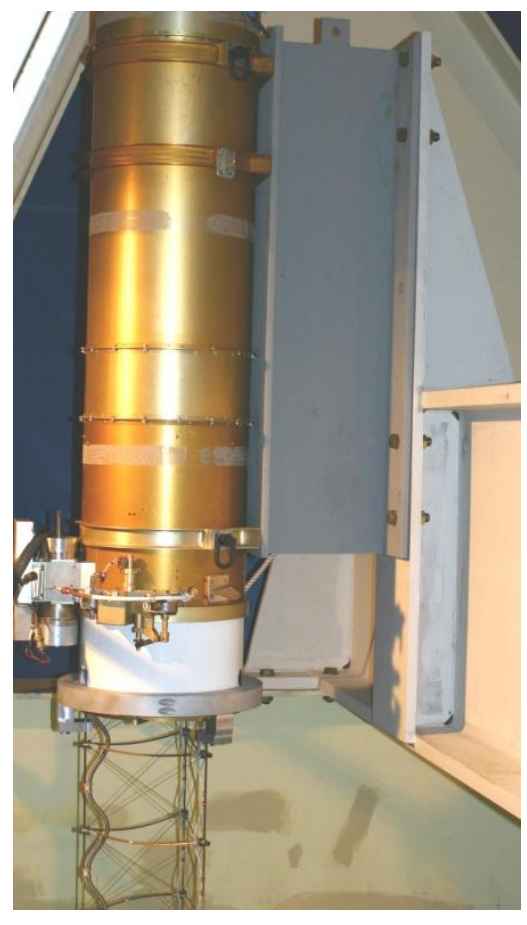

Mounted SAFE Mast Canister System

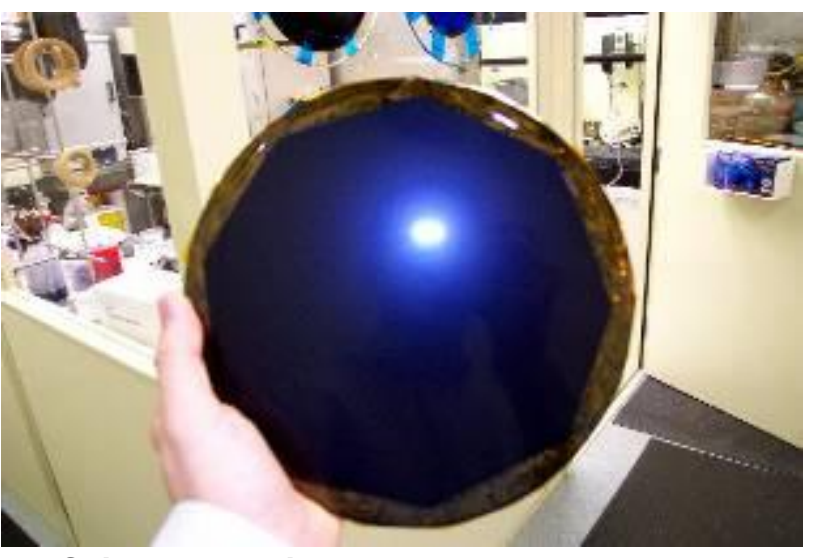

Sail sample with carbon black nanotubes 


\section{TRL Assessment Process Flowchart}

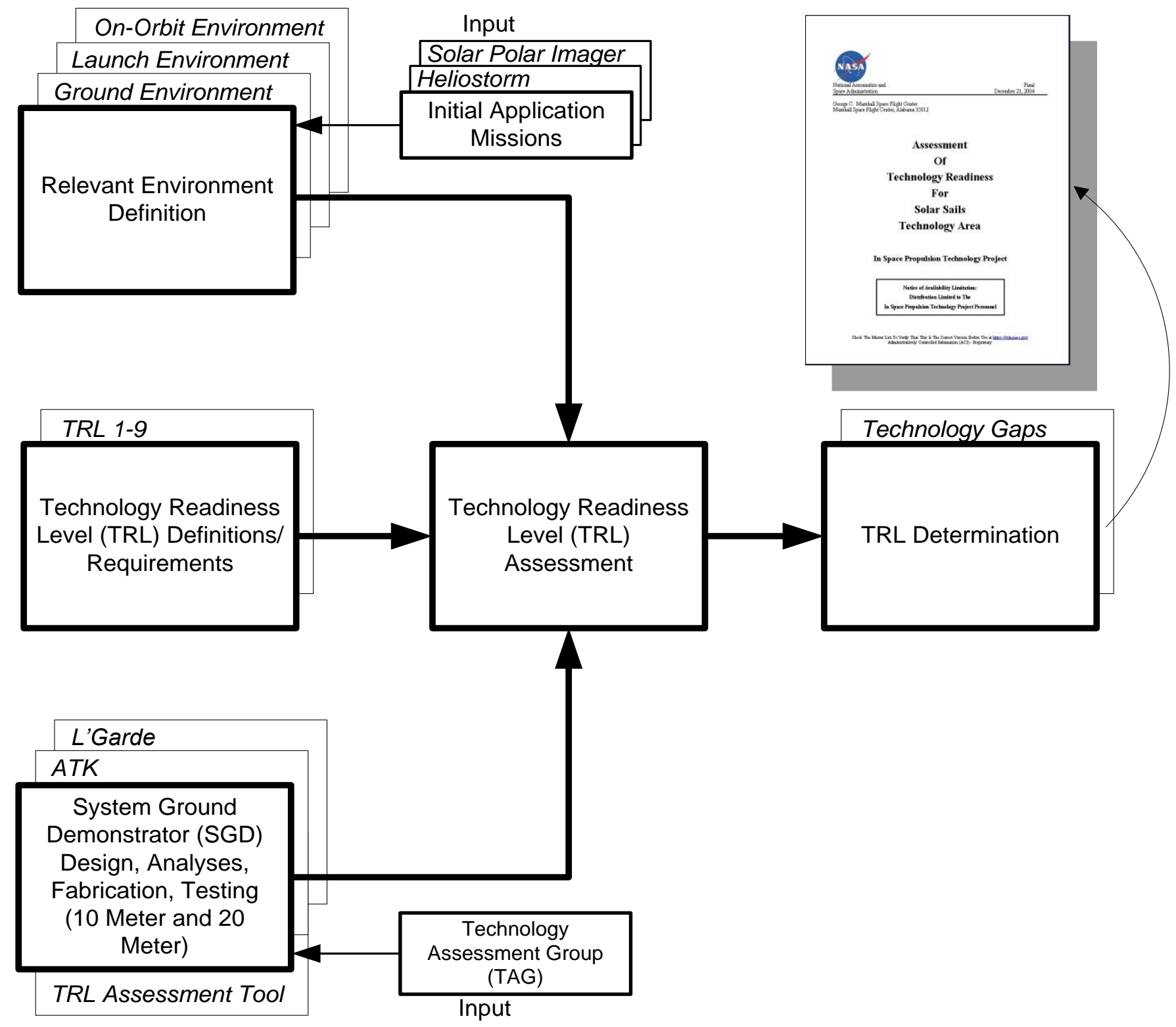




\section{TRL 3-5 Assessment Worksheet (Example)}

L'GARDE 10m MAST TRL ASSESSMENT

\begin{tabular}{|c|c|c|c|c|c|c|c|c|c|c|c|}
\hline TRL LEVEL & COMMENTS & CONDITIONS & 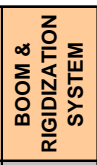 & 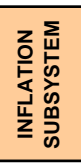 & 簂 & 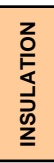 & 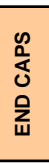 & 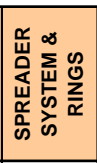 & 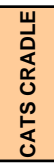 & 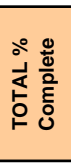 & NOTES \\
\hline \multirow{3}{*}{\begin{tabular}{|l|} 
TRL 3: \\
Analytical and \\
experimental \\
critical function \\
and/or \\
characteristic \\
proof of concept \\
achieved in a \\
laboratory \\
environment \\
\end{tabular}} & \multirow{3}{*}{$\begin{array}{l}\text { At this step in the maturation process, active research and } \\
\text { development (R\&D) is initiated. This includes both } \\
\text { analytical studies to set the technology into an } \\
\text { appropriate context and laboratory-based studies to } \\
\text { validate empirically that the analytical predictions are } \\
\text { correct. These studies and experiments validate the } \\
\text { benefits offered by the technology advancement to the } \\
\text { applications/concepts formulated at TRL } 2 \text {. }\end{array}$} & $\begin{array}{l}\text { Laboratory tests have demonstrated that the technology } \\
\text { advance as predicted by the analytical model and has the } \\
\text { potential to evolve to a practical device. }\end{array}$ & 100 & 100 & 100 & 100 & 100 & 100 & 100 & 100 & \multirow{3}{*}{$\begin{array}{l}\text { The detailed relevant environment was not defined by } \\
\text { the government to the contractors in the NRA, only a } \\
\text { generic Design Reference Mission. The NASA TRL } \\
\text { Assessment Document fully defines the relevant } \\
\text { environment for solar sail technology at the .5 to } 1 \text { AU } \\
\text { utilizing a Delta II launch vehicle. This definition was } \\
\text { done at the start of Phase III of their contracts and } \\
\text { therefore the contractors were given credit for relevant } \\
\text { environment definition at TRL } 3 \text {. }\end{array}$} \\
\hline & & $\begin{array}{l}\text { Analytical models both replicate the current performance of } \\
\text { the technology advance and predict its performance when } \\
\text { operating in a breadboard environment. }\end{array}$ & 100 & 100 & 100 & 100 & 100 & 100 & 100 & 100 & \\
\hline & & \begin{tabular}{|l} 
A determination of the "relevant environment" for the \\
technology advance has been made. (See Note)
\end{tabular} & 100 & 100 & 100 & 100 & 100 & 100 & 100 & 100 & \\
\hline \multirow{3}{*}{\begin{tabular}{|l|} 
TRL 4: \\
Component \\
and/or \\
breadboard \\
validated in a \\
laboratory \\
environment
\end{tabular}} & \multirow{3}{*}{\begin{tabular}{|l|} 
Following successful "proof-of-concept" work, basic \\
technological elements must be integrated to establish \\
that the "pieces" will work together to achieve concept- \\
enabling levels of performance for a component and/or \\
breadboard. This validation must be devised to support \\
the concept that was formulated earlier, and should also \\
be consistent with the requirements of potential system \\
applications. The validation is relatively "lowfidelity" \\
compared to the eventual system; it could be composed of \\
ad hoc discrete components in a laboratory.
\end{tabular}} & $\begin{array}{l}\text { A "component" or "breadboard" version of the technology } \\
\text { advance will have been implemented and tested in a } \\
\text { laboratory environment. }\end{array}$ & 100 & 100 & 100 & 100 & 100 & 100 & 100 & 100 & \multirow{3}{*}{$\begin{array}{l}\text { Models used to predict propulsion performance in a } \\
\text { relevant environment. Propulsion qualification tests } \\
\text { cannot be conducted on the ground for a solar sail. } \\
\text { Analytical models not developed for other relevant } \\
\text { natural or induced environments }\end{array}$} \\
\hline & & $\begin{array}{l}\text { Analytical models of the technology advance fully replicate } \\
\text { the TRL } 4 \text { test data. }\end{array}$ & 100 & 100 & 100 & 100 & 100 & 100 & 100 & 100 & \\
\hline & & $\begin{array}{l}\text { Analytical models of the performance of the component or } \\
\text { breadboard configuration of the technology advance predict } \\
\text { its performance when operated in its "relevant environment" } \\
\text { and the environments to which the technology advance } \\
\text { would be exposed during qualification testing for an } \\
\text { operational mission. See NOTE }\end{array}$ & 100 & 100 & 100 & 100 & 100 & 100 & 100 & 100 & \\
\hline \multirow{8}{*}{\begin{tabular}{|l|} 
TRL 5: \\
Component \\
and/or \\
breadboard \\
validated in a \\
relevant \\
environment \\
\end{tabular}} & \multirow{8}{*}{$\begin{array}{l}\text { At this TRL, the fidelity of the environment in which the } \\
\text { component and/or breadboard has been tested has } \\
\text { increased significantly. The basic technological elements } \\
\text { must be integrated with reasonably realistic supporting } \\
\text { elements so that the total applications (component-level, } \\
\text { sub-system level, or system-level) can be tested in a } \\
\text { "relevant environment". }\end{array}$} & \multirow{3}{*}{\begin{tabular}{|l|} 
The "relevant environment" is fully defined. See NOTE \\
The technology advance has been tested in its "relevant \\
environment" throughout a range of operating points that \\
represents the full range of operating points similar to those \\
to which the technology advance would be exposed during \\
qualification testing for an operational mission. See NOTE
\end{tabular}} & 100 & 100 & 100 & 100 & 100 & 100 & 100 & 100 & \multirow{4}{*}{$\begin{array}{l}\text { The detailed relevant environment was not defined by } \\
\text { the government to the contractors in the NRA, only a } \\
\text { generic Design Reference Mission. The NASA TRL } \\
\text { Assessment Document fully defines the relevant } \\
\text { environment for solar sail technology at the . . to } 1 \text { AU } \\
\text { utilizing a Delta Il launch vehicle. This definition was } \\
\text { done at the start of Phase Ill of their contracts and } \\
\text { therefore the contractors did not test components at a } \\
\text { fully defined relevanet environment. }\end{array}$} \\
\hline & & & & AVERAG & OF NAT & $\mathrm{AL}, \mathrm{LAL}$ & \& GR & UND ENVIF & NMEN & & \\
\hline & & & 62.5 & 62.5 & 100 & 75 & 100 & 62.5 & 62.5 & 75 & \\
\hline & & \multirow{3}{*}{$\begin{array}{l}\text { Component or breadboard has been tested in the } \\
\text { relevant natural environment } \\
\text { Component or breadboard has been tested in the } \\
\text { relevant launch environment } \\
\text { Component or breadboard has been tested in the } \\
\text { relevant ground environment }\end{array}$} & 50 & 50 & 100 & 50 & 100 & 50 & 50 & & \\
\hline & & & NA & NA & NA & NA & NA & NA & NA & & \multirow{4}{*}{$\begin{array}{l}\text { Natural Environment - inflation system leaks - new } \\
\text { material needed; no UV, e, p on boom material or } \\
\text { spreader system (kapton pockets, kevlar lines), no e, p } \\
\text { on insulation } \\
\text { Ground environment - lines showed signs of chaffing - } \\
\text { possible ground shipping issue. Assembly process and } \\
\text { procedure is not repeatable and no method available to } \\
\text { verify correct assembly. Limited test life (limited number } \\
\text { of deployments without damage) } \\
\text { Models - no deployment dynamics model, no charging }\end{array}$} \\
\hline & & & 75 & 75 & 100 & 100 & 100 & 75 & 75 & & \\
\hline & & $\begin{array}{l}\text { Analytical models of the technology advance replicate the } \\
\text { performance of the technology advance operating in the } \\
\text { "relevant environment" }\end{array}$ & 75 & 75 & 75 & 75 & 75 & 75 & 75 & 75 & \\
\hline & & $\begin{array}{l}\text { Analytical predictions of the performance of the technology } \\
\text { advance in a prototype or flight-like configuration have been } \\
\text { made. }\end{array}$ & 100 & 100 & 100 & 100 & 100 & 100 & 100 & 100 & \\
\hline
\end{tabular}


TRL Assessment

Results Comparison

\begin{tabular}{|l|c|c|c|c|}
\hline Vendor & $\begin{array}{c}\text { Post 10M } \\
\text { TRL 5 } \\
\text { Completion } \\
\text { Average }\end{array}$ & $\begin{array}{c}\frac{\text { Post 20M }}{\text { TRL 5 }} \\
\text { Completion } \\
\text { Average }\end{array}$ & $\begin{array}{c}\frac{\text { Post 10M }}{\text { TRL 6 }} \\
\text { Completion } \\
\text { Average }\end{array}$ & $\begin{array}{c}\text { Post 20M } \\
\text { TRL 6 } \\
\text { Completion } \\
\text { Average }\end{array}$ \\
\hline ATK & $\mathbf{7 6 \%}$ & $\mathbf{8 9 \%}$ & $\mathbf{6 0 \%}$ & $\mathbf{8 6 \%}$ \\
\hline L'Garde & $\mathbf{7 5 \%}$ & $\mathbf{8 4 \%}$ & $\mathbf{6 8 \%}$ & $\mathbf{7 8 \%}$ \\
\hline
\end{tabular}

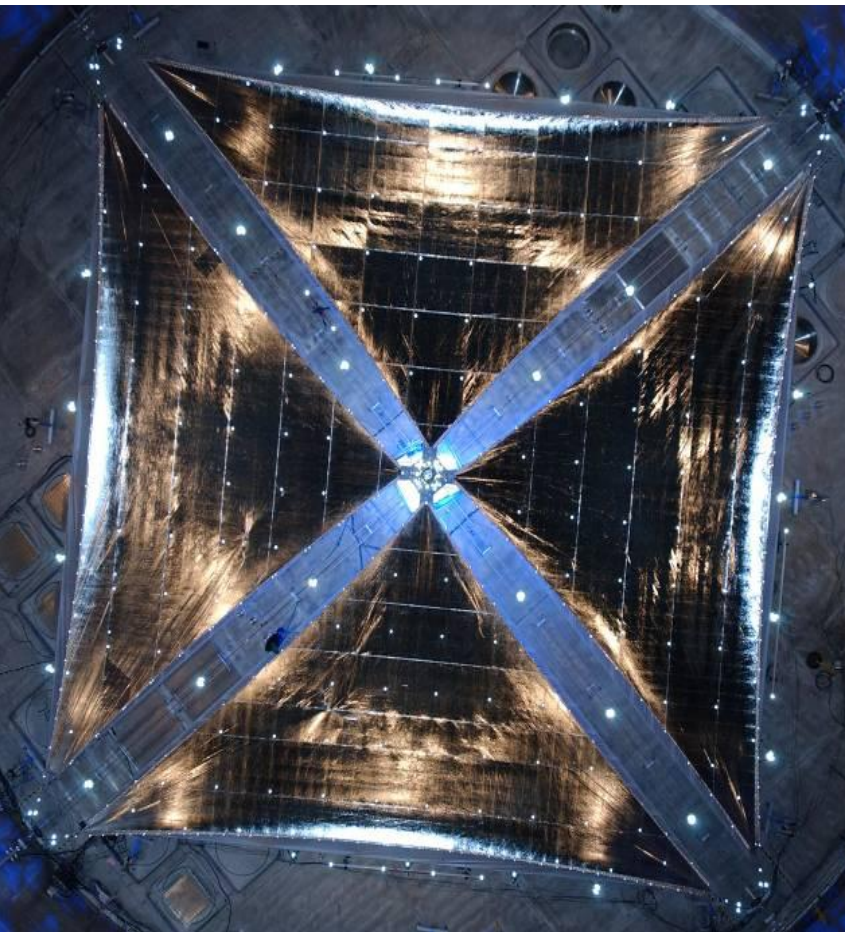

ATK

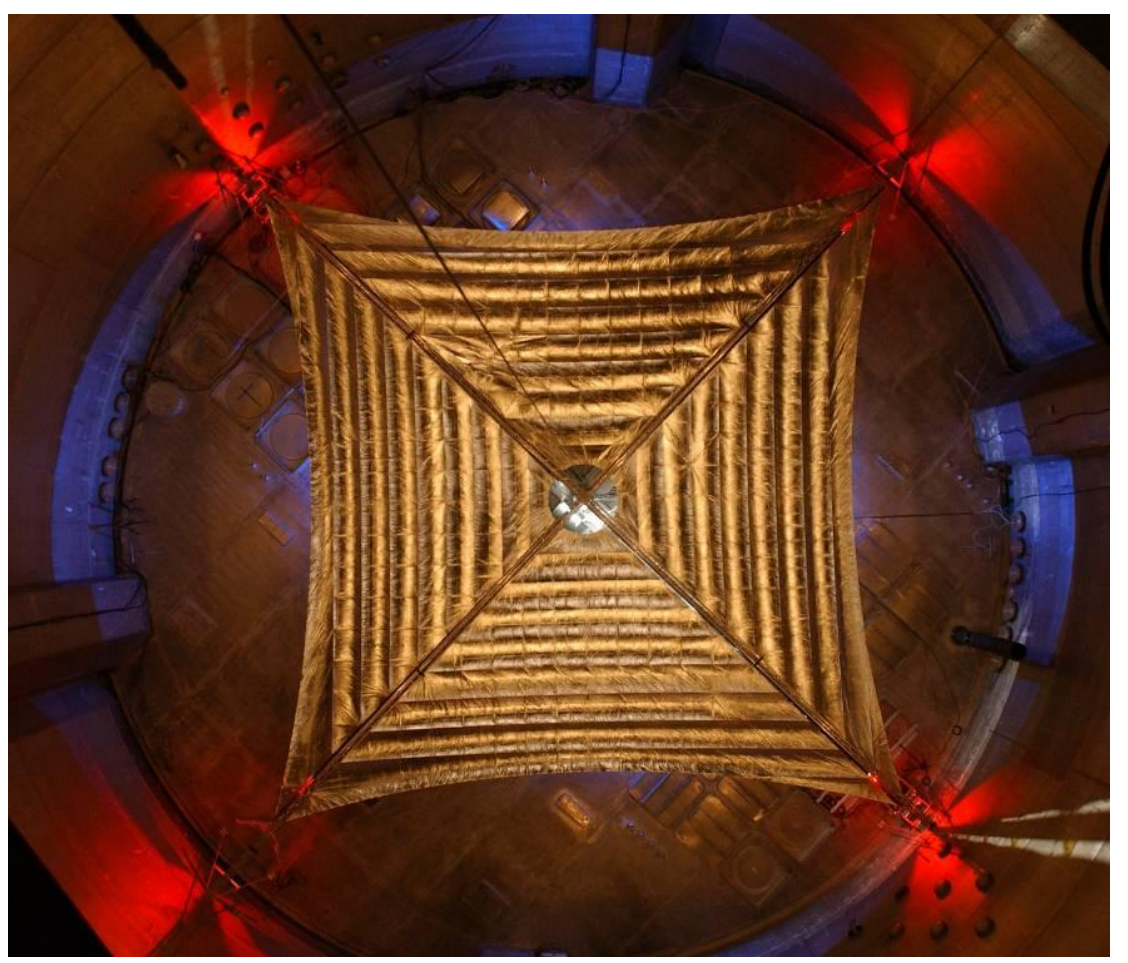

L'Garde 


\section{Technology Gaps}

\section{Solar Sail Technology Gaps}

No modeling of deployment and deployment dynamics has been done.

Materials environmental testing is incomplete or in some cases has not been done at all. No testing has been done on seams, bonds, adhesives, ground straps, ripstop, sequencers, targets, inflatable booms or graphite epoxy components.

Meteoroid/orbital debris (M/OD) testing has been very limited. M/OD testing should be done with the integrated ripstop.

Scalability between the $10 \mathrm{~m}$ and $20 \mathrm{~m}$ designs is in question due to the design changes occurring after the $10 \mathrm{~m}$ system testing was complete.

Scalability to a science mission needs to be studied in detail. Facilities do not exist to manufacture, assemble or test a large-scale sail system. Current manufacturing and assembly processes for the most part are manual and labor intensive.

\section{Post 10M System Impacts}

Deployment dynamics could impact the design and operation of a solar sail system, which could cause significant design changes. Significant design changes could invalidate previous model validation efforts.

Results of materials testing could necessitate materials changes and impact design.

The functionality of ripstop has not been tested or proven. Tear resistance is imperative to a good flight design.

Significant design changes, as well as the inclusion of the attitude control system in the $20 \mathrm{~m}$ design, impacts the ability to assess the scalability between the $10 \mathrm{~m}$ and $20 \mathrm{~m}$ designs. The process for evaluating model scaling has not been established. Scalability between ground demos needs to be established so that models can validate and then used to support much larger flight designs.

Feasibility of manufacturing a 10-20m design has been proven but the processes and facilities to manufacture a much larger flight system have not been proven. Current facilities and techniques appear to be inadequate to handle a larger sail system and fabrication scalability has not been proven. New techniques, processes, and facilities need to be developed for a larger sail system. A rigorous study should be conducted to look at all of the factors involved in fabricating, assembling and testing a larger sail.

\section{M System Gap Update}

- ATK had accelerometers on their tips for deployment and L'Garde used photogrammetry and video to view boom tips.

- L'Garde experienced asymmetric deployment issues during vacuum testing. Maintaining attitude control and stability during deployment is critical and L'Garde has conducted an initial deployment simulation tool. Based on the 20-m system

- Ground System Demonstrator (GSD) material testing has been done in support of L1 Diamond $(.95 \mathrm{AU})$ and Solar Polar Imager $(.5 \mathrm{AU})$, considered to be the Initial Application Missions (IAM).

- Additional testing that was done on the L'Garde sail material indicates an issue with coated Mylar in a VUV environment. Material loses strength in 3 years and disintegrates in a 6 years. Final analyses of the test results are underway.

- No testing has been done to date on seams, booms, beams, targets, repairs or elements.

- Limited ATK ripstop testing done by SRS.

- L'Garde ripstop demonstrated during deployment testing.

- L'Garde boom insulation needs investigation. MOD impact on boom rigidity could be an issue.

- Data on model scalability between the 10 and $20 \mathrm{M}$ systems is TBD.

- The sensitivity of the sail models to design changes has not been determined.

- Limited additional information between the $10 \mathrm{M}$ and $20 \mathrm{M}$ ground demonstrator systems.

- An assessment of facilities for ambient deployment was conducted by ISPT with several sites identified.

- ATK has developed a beam/longeron splice technique.

- L'Garde has manufactured booms up to $50 \mathrm{~m}$ in length for another program 
Mission:

- Delta II RH-DPAF (also fully compatible with Pegasus XL)

- Orbit: $1250 \mathrm{~km}$ attitude circular, dawn-dusk, Sun synchronous

- After checkout, 2-month technology validation

- Perigee-lowering at mission end for disposal

Spacecraft • Orbital

- High Heritage MicroStar bus

- GPS for orbitt/thruist determination

- 3-axis momentum bias ACS

- Onboard Hydrazine Propulsion

- S-band Up: 2 kbps

- S-band Down: 2.25 Mpbs

- Li lon Battery

$34.5 \mathrm{~m}$

Sail Camera System - The Planetary Society

- 4 hub-mounted, engineering-class cameras

Translation Stage

- Changes center of mass for attitude control

- Displaces bus mass in plane of sail

by \pm 0.4 meter

- Competitively procured

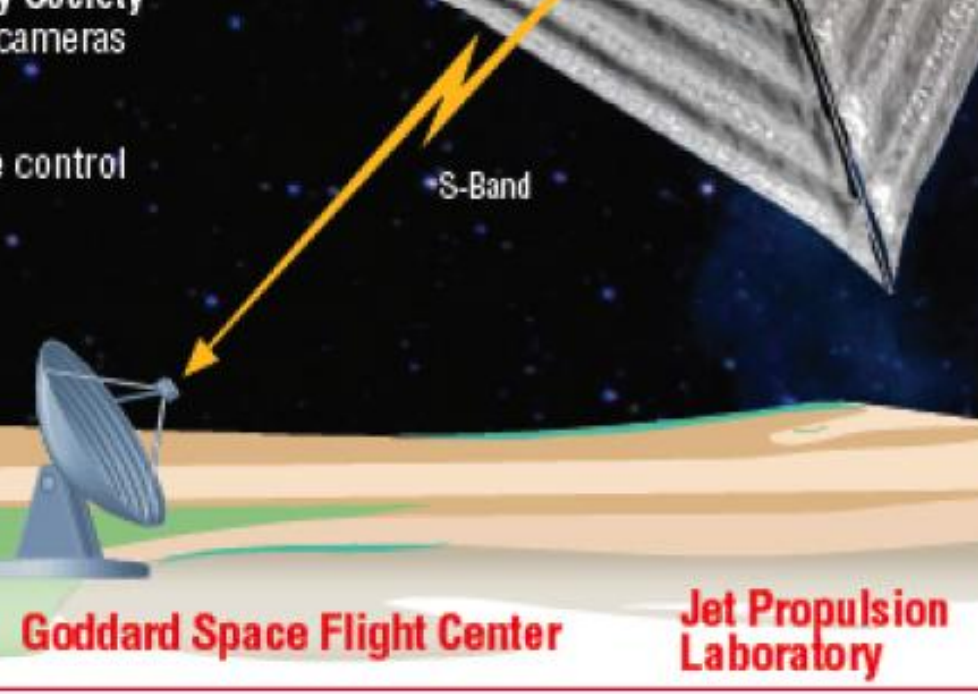

\section{-}

Sail Propulsion System • L'Garde Metallized, 1,000 $\mathrm{m}^{2}$ Mylar sail

(1/50th thickness of a human hair)

- Size equivalent to the infield of a major league baseball diamond - Anflatable-deployed, thermally rigidized booms

- Technologies Validated - Sail Deployment

- Control

- Thrust Performance

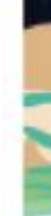

L'Garde Orbital

Tustin, CA

- Solar Sail

- Sail

Electronics and Structure
OSC Mission
Operations Center
Dulles, VA

- Spacecraft Bus

- System Integration and Test

- Mission

Operations
NASA Greenbelt, MD

Ground

Network

- 11 m Dishes

- Alaska

- Wallops
- Project Management

- Systems Engineering

- Mission Assurance

- Technology Validation

- Education/Public Outreach
Pasadena, CA

- Thrust

Estimation

- Inflation

Deployment

Modeling

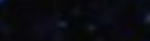

GPS

S-Band

- TDRSS

(tor critlical arant telematry) 


\section{NASA NanoSail-D \\ Making Lemonade from Lemons}

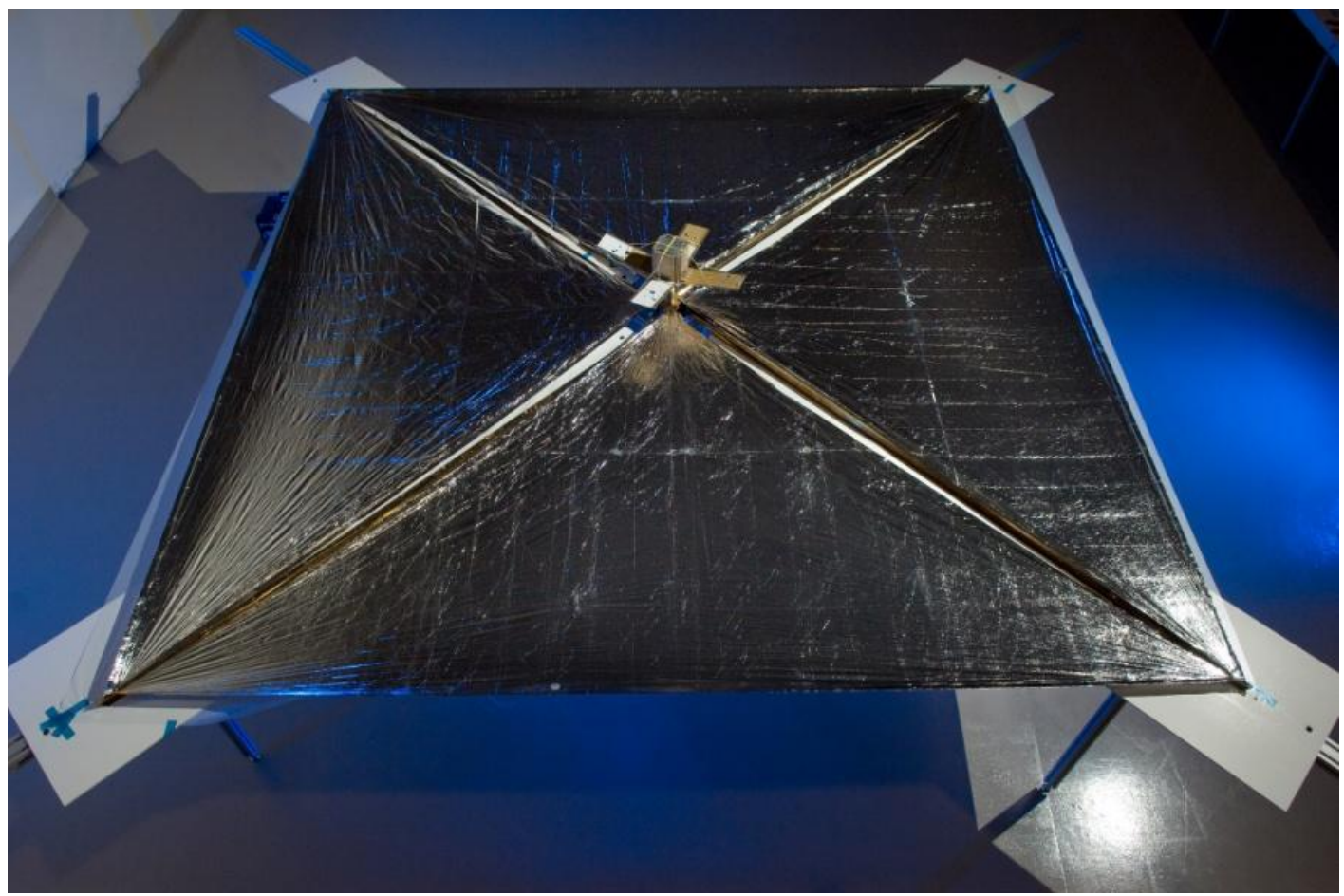

- NanoSail-D was born in 2007

- $10 \mathrm{~m}^{2}$ sail

- No program funding but leftover Ground Demonstration Hardware - How do we make use of it? 


\section{Project Overview}

- $\quad$ Minimum Success Criteria

- Design, fabrication, test and delivery of a flightready satellite to the launch site within budget on an extremely tight 6 month schedule.

\section{- Full Success Objectives}

- Primary: First solar sail deploy in space

- Secondary

- Solar Sail performance assessment

- Drag sail assessment

- Pioneer new project processes

- Deliverables

- Primary Solar Sail Payload Assembly

- Spare Solar Sail Payload Assembly

- Payload Mockup for ARC Bus development

- Poly PicoSat Orbital Deployer

\section{- Sponsors}

- MSFC Center Director

- ARC Center Director

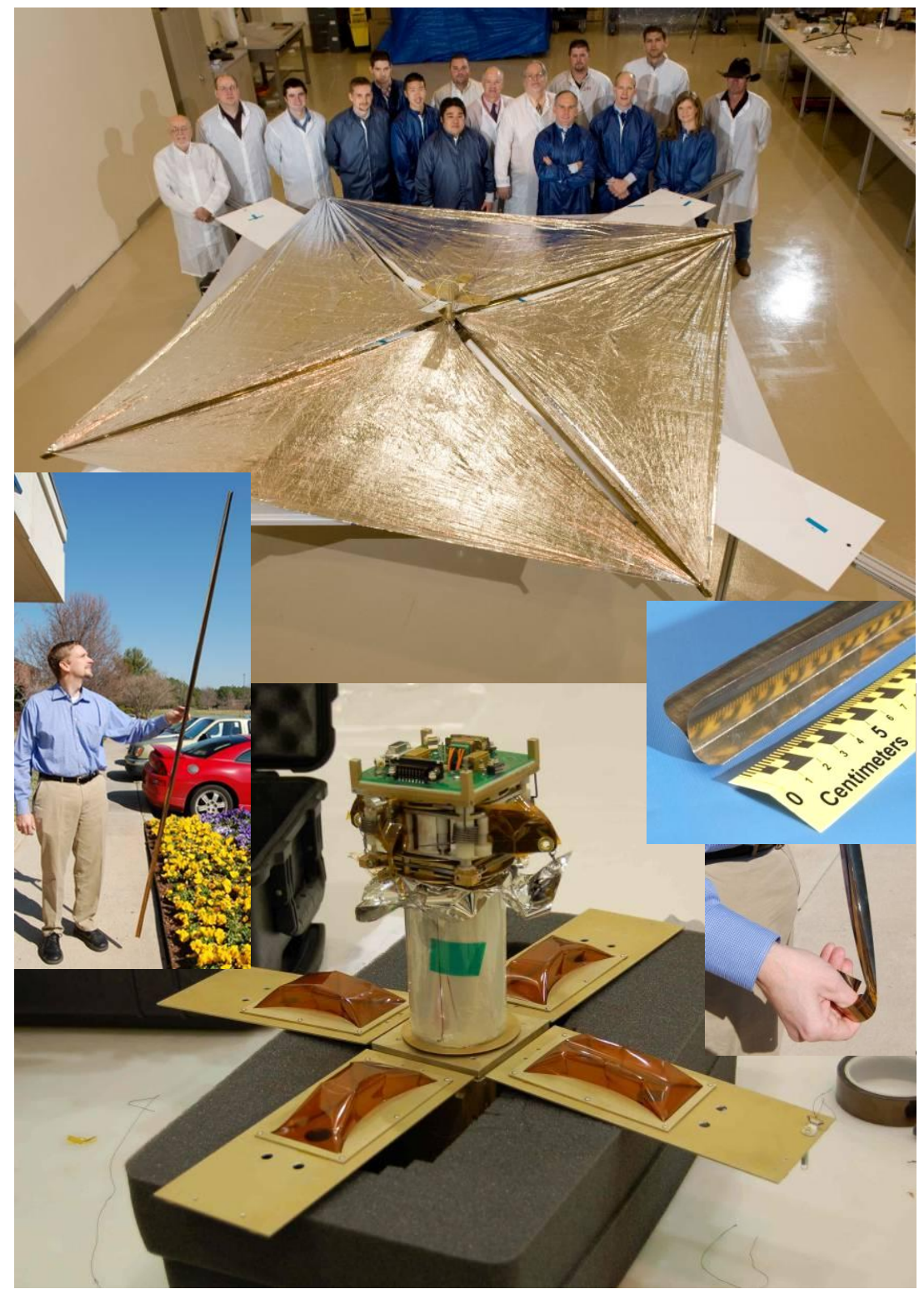




\section{On-Orbit Stowed Configuration}

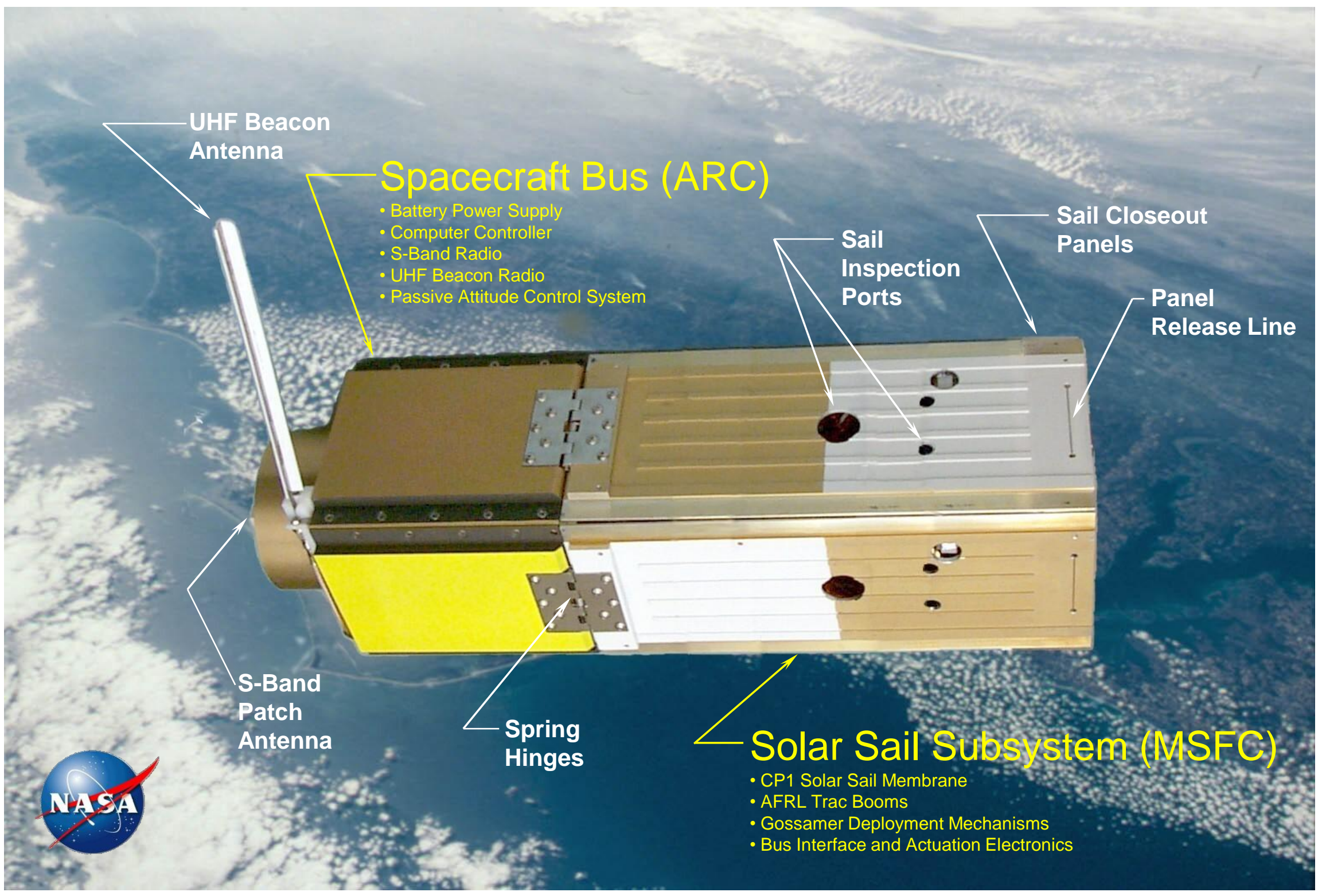




\section{Deployment Video}

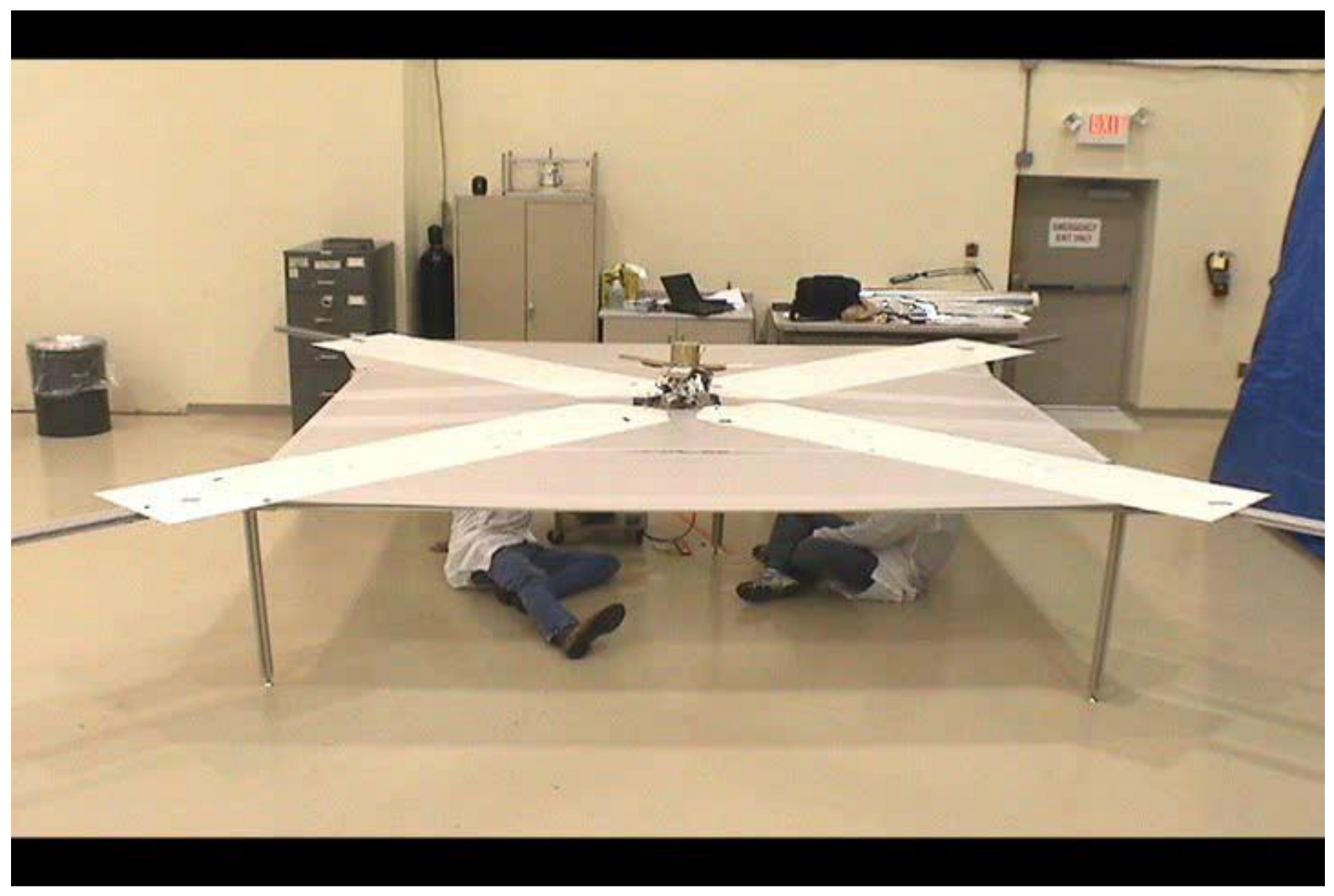




\section{Major Milestones}

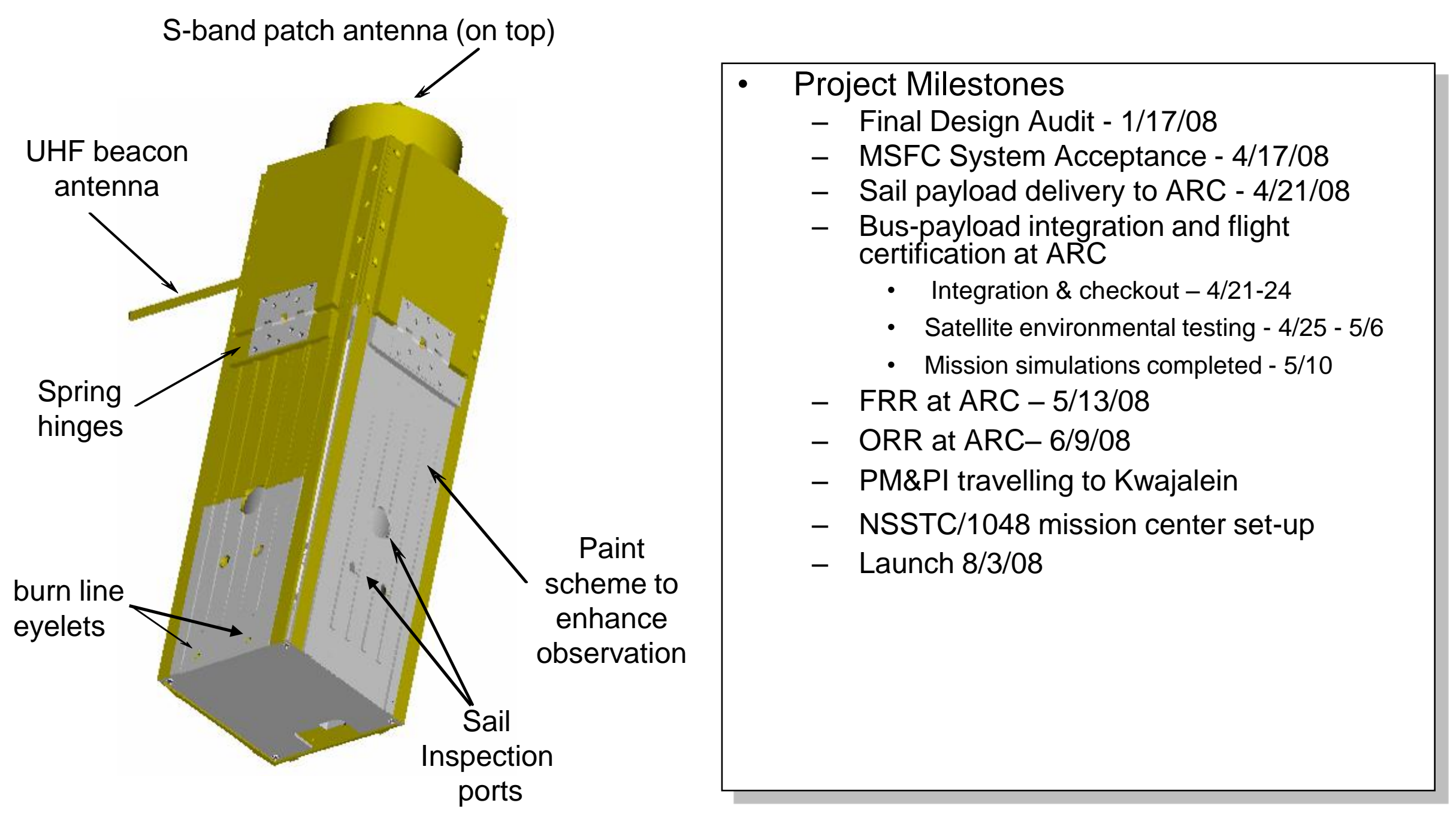

Stowed Configuration 


\section{NanoSail-D Flight Launch Attempted in 2008}

- Launch

- Falcon-1, flight 3

- Kwajalein, Missile Range

- Primary payload: AFRL PnPSat

- Secondary P-POD payloads (2)

- PharmaSAT-1

- DeOrbitSail (DOS)
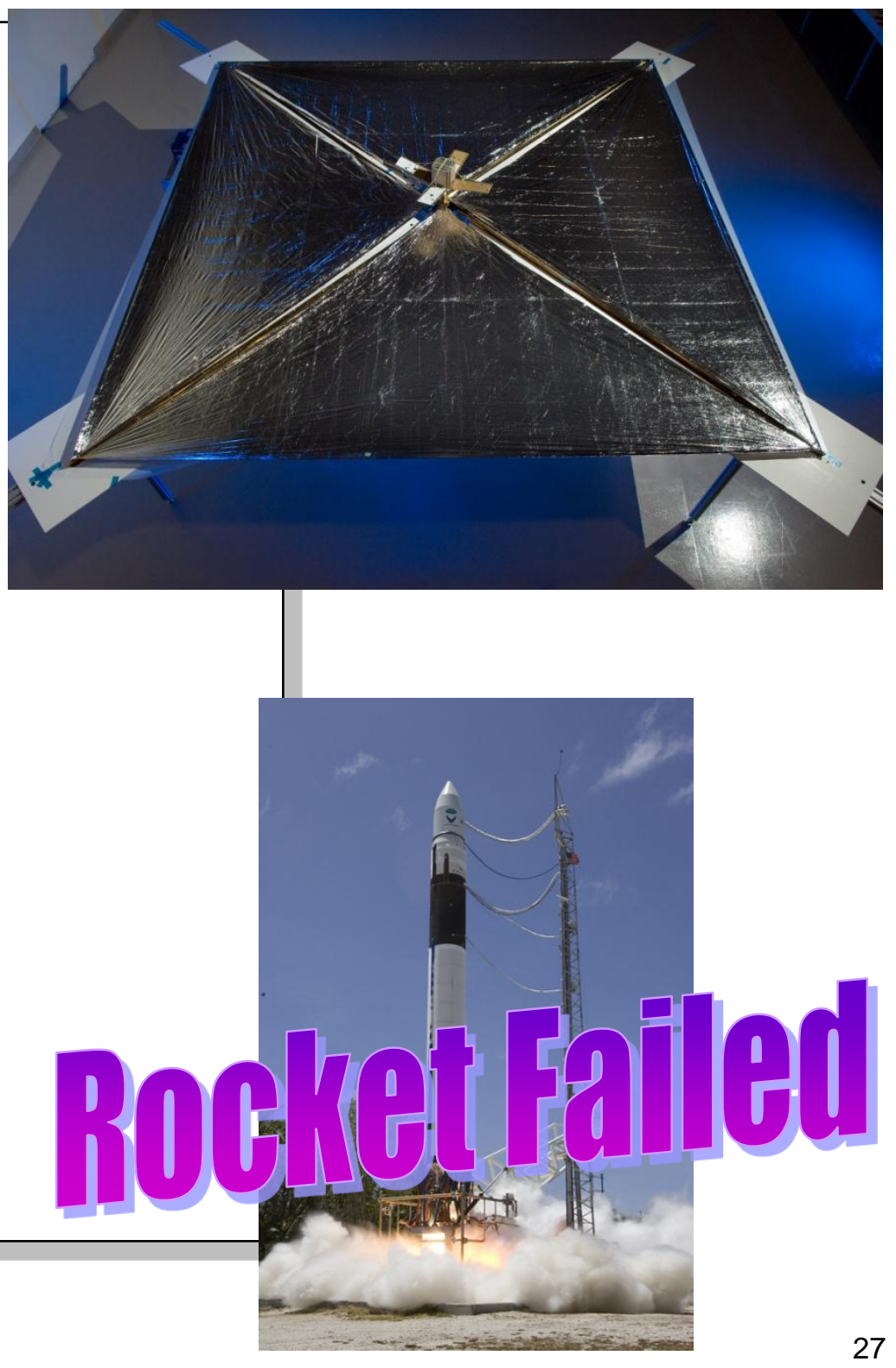
NanoSail-D Flight Spare to Launch in 2010

- Launch

- Falcon-1, flight 3

- Kwajalein, Missile Range

- Primary payload: AFRL PnPSat

- Secanda J

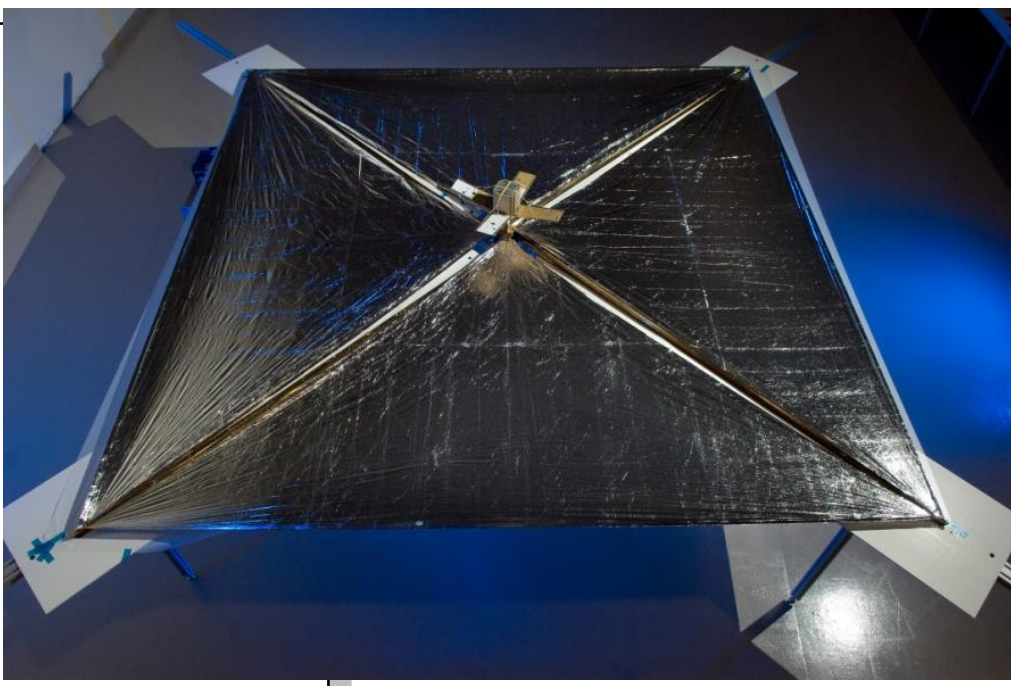

- DuoroitSail (DOS) 


\section{On-Orbit Deployed Configuration}

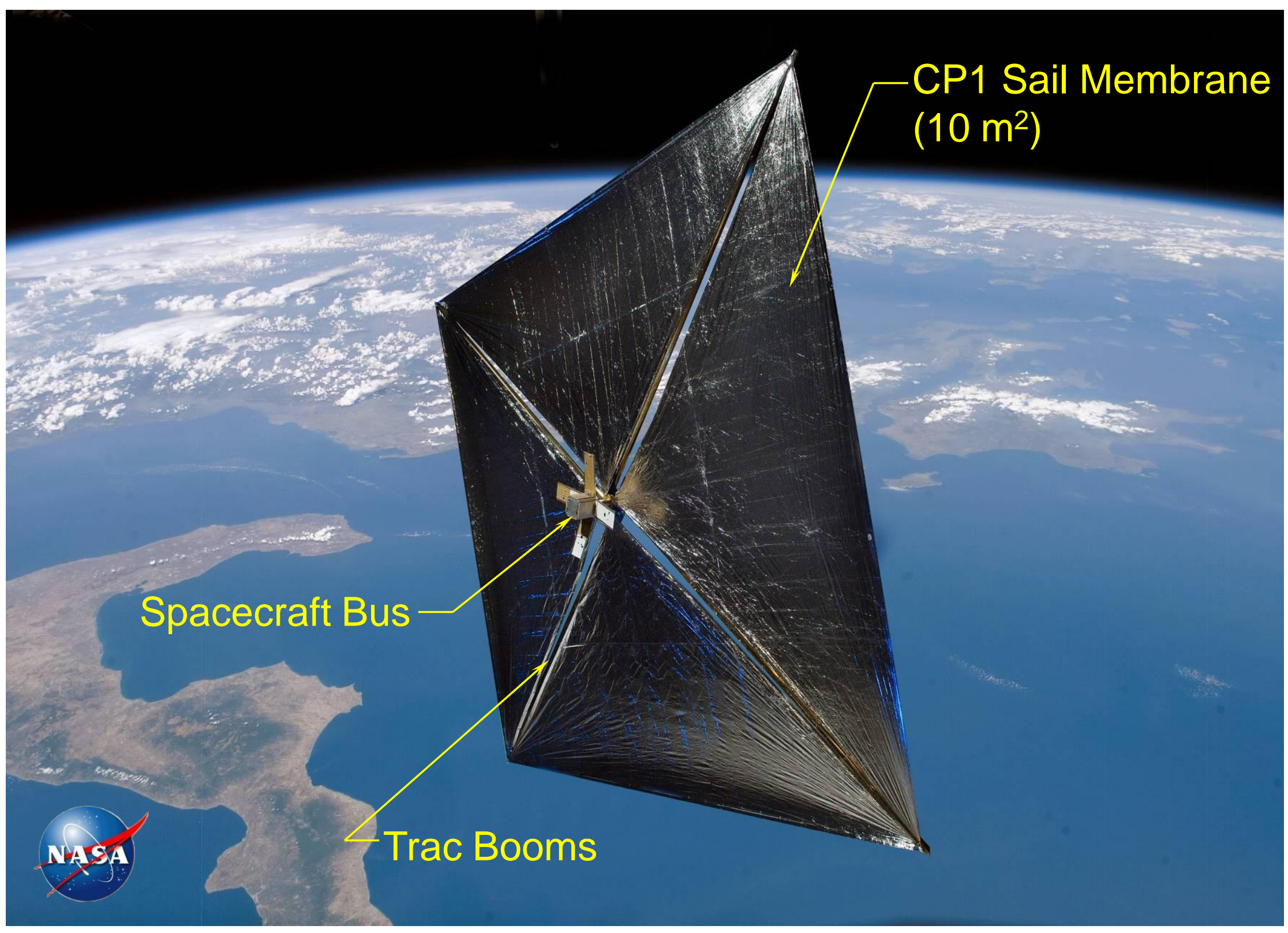




\section{On-Orbit Performance Predictions}

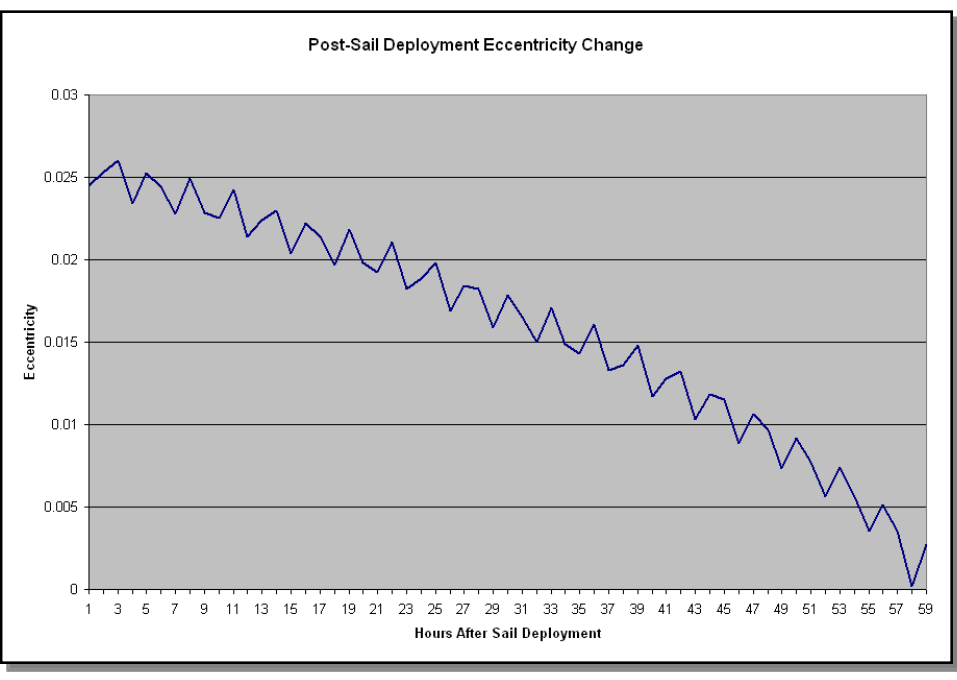

Eccentricity

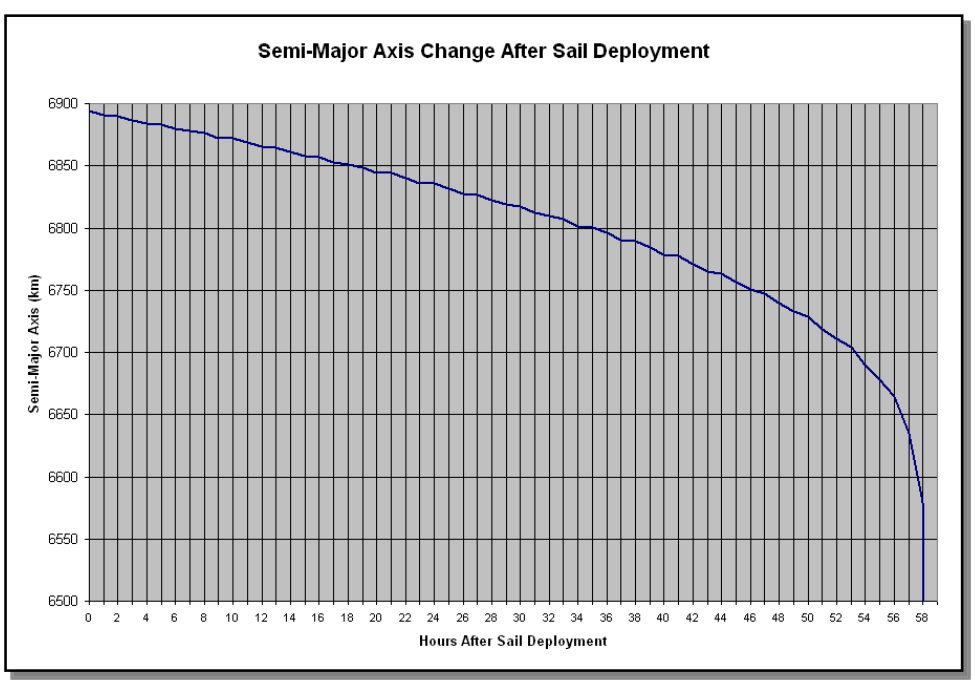

Semi-Major Axis

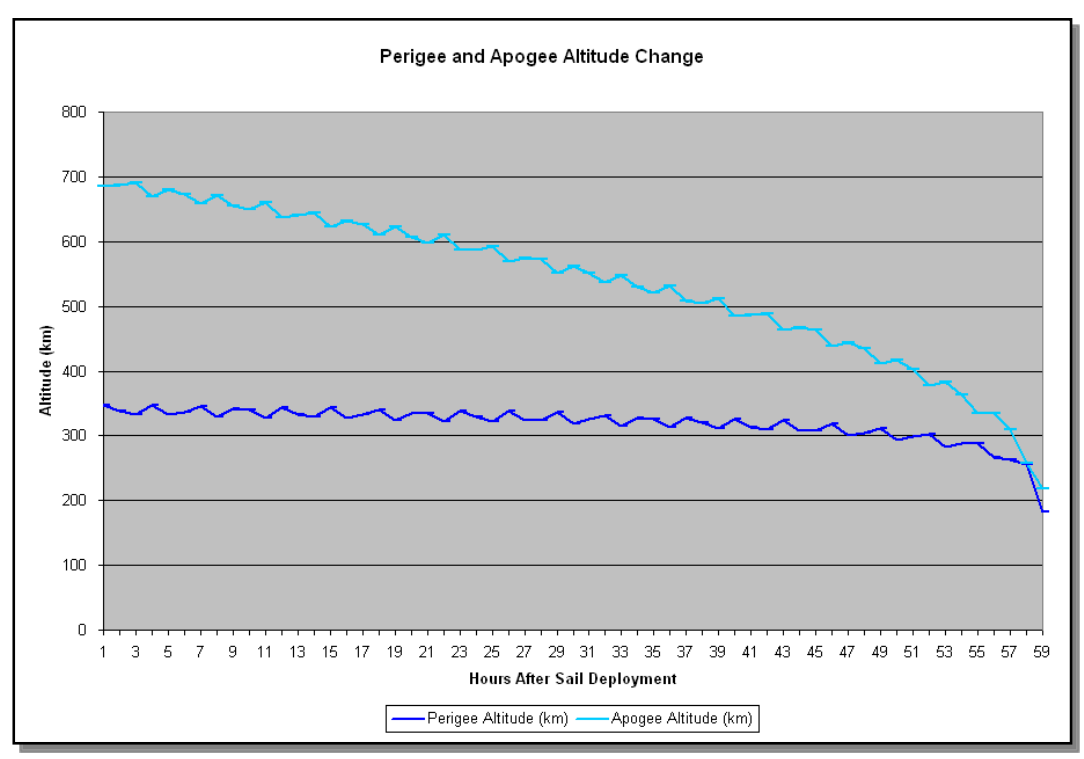

Perigee/Apogee Altitude 


\section{On-Orbit Performance Predictions}

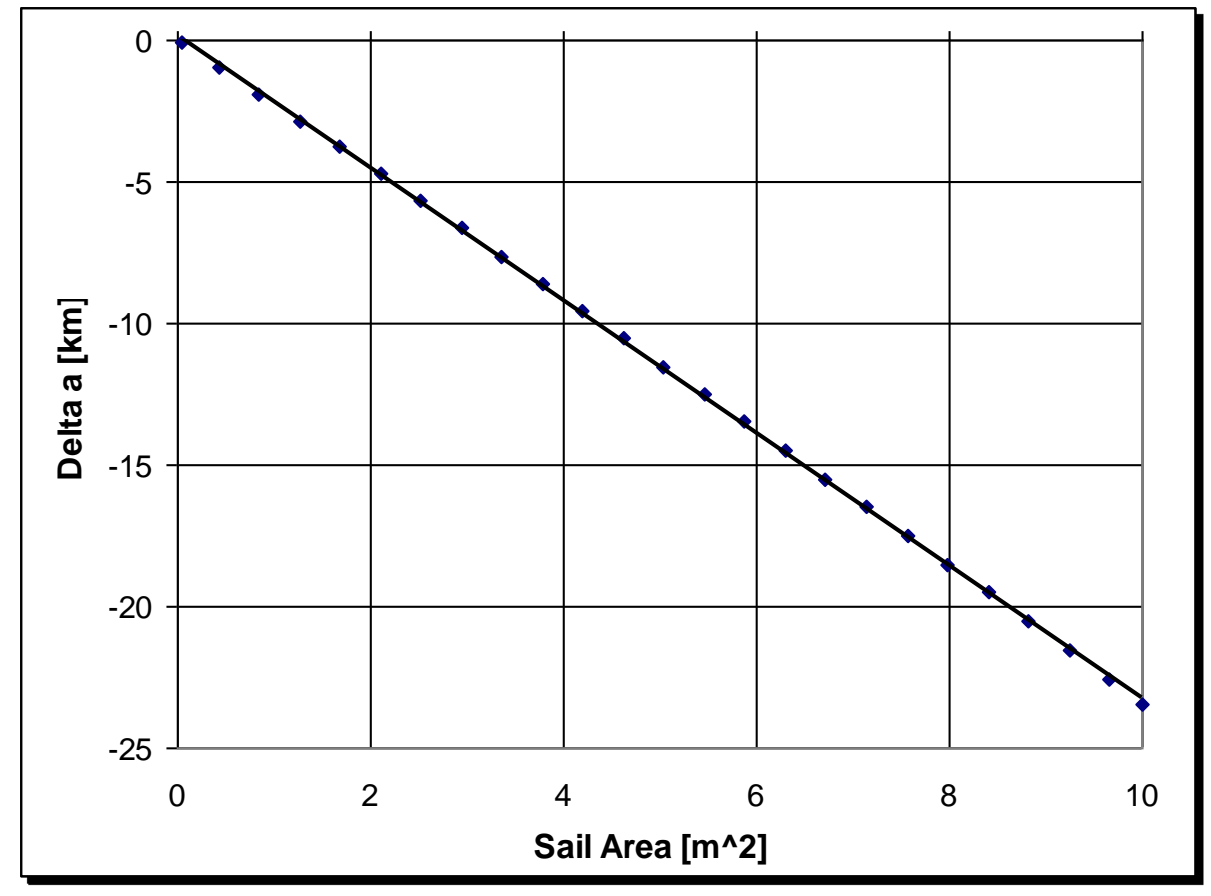

Mission Duration as a Function of

\section{Orbit Decay as a Function of Sail} Area (24 hr Time Period)*

\section{Sail Area*}

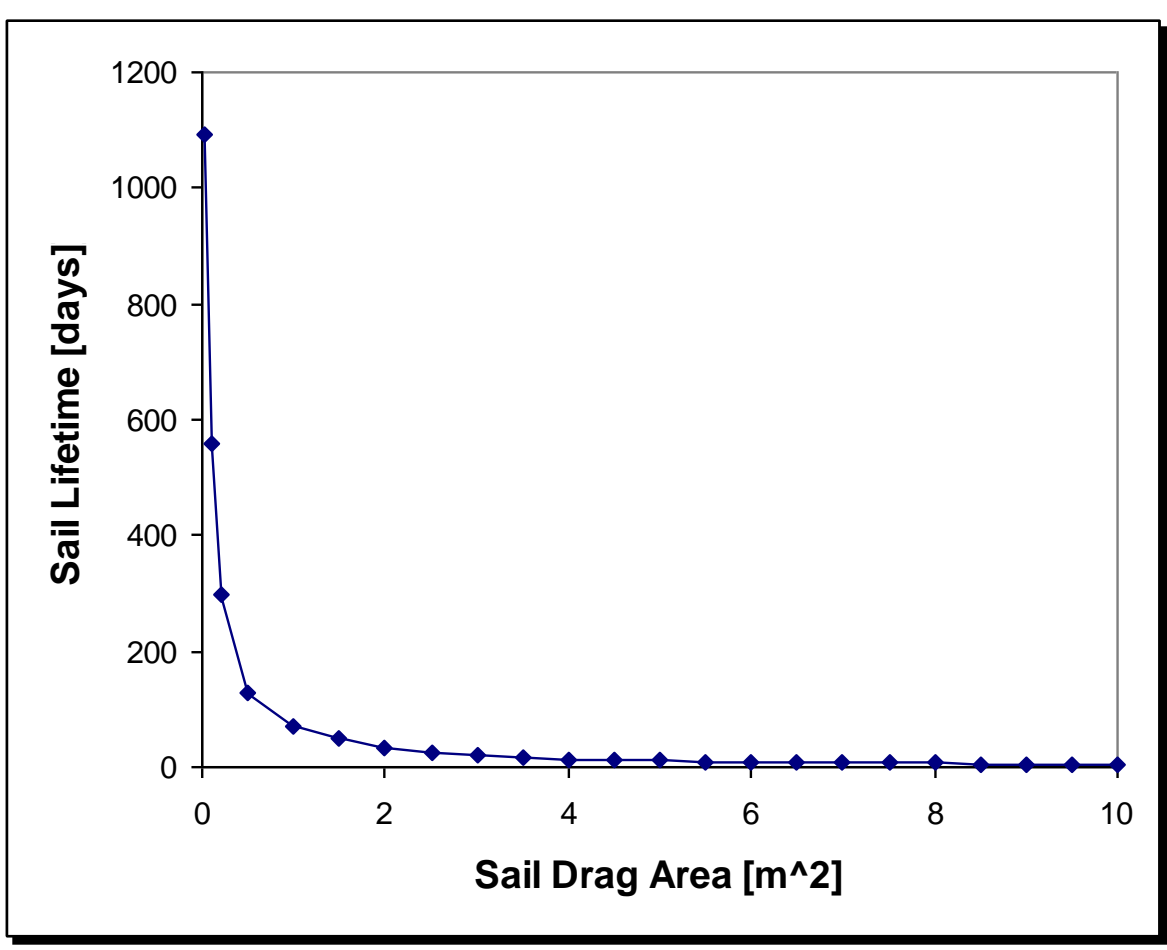

